\title{
Redrafting the Ontology of Scientific Change
}

\author{
Hakob Barseghyan
}

IHPST, University of Toronto

hakob.barseghyan@utoronto.ca

\section{Keywords}

theoretical scientonomy, ontology of scientific change, ontology of epistemic elements, method, methodology, method employment, method acceptance, norm employment, employment record, acceptance record, explicit, implicit, definition, scientific mosaic

\begin{abstract}
Recent developments in theoretical scientonomy coupled with a reflection on the practice of the Encyclopedia of Scientonomy all suggest that the ontology of scientific change currently accepted in scientonomy has serious flaws. The new ontology, suggested in this paper, solves some of the issues permeating the current ontology. Building on Rawleigh's suggestion, it considers a theory as an attempt to answer a certain question. It also introduces the category of definition as a subtype of theory. It also reveals that methods and methodologies of the currently accepted ontology do not differ from the perspective of their propositional content and, thus, belong to the same class of epistemic elements. This is captured in the new definition of method as a set of criteria for theory evaluation. It is also argued that methods are a subtype of normative theories. It is shown that normative theories of all types, including methods, ethical norms, and aesthetic norms, can be both accepted and employed. Finally, a new definition of scientific mosaic is suggested to fit the new ontology.
\end{abstract}




\section{Introduction}

Any general theory that attempts to describe and explain changes in a certain domain usually contains two major components - a certain ontology of the entities and relations that undergo change in that domain and a certain dynamics of how these entities and relations supposedly change through time. For example, our physical theories tell us both what type of entities and relations exist out there in the physical universe (e.g. quarks, leptons, bosons) and how these entities and relations change through time. The same goes for virtually any theory from natural or social science: they normally posit a certain ontology of their domain and attempt to unearth its dynamics. In that sense, the current theory of scientific change accepted in the field of scientonomy is no exception: it comes with a certain ontology of epistemic agents, elements, and stances, and suggests a set of laws that presumably tells us how the stances taken by different epistemic agents towards different elements change over time. In the scientonomic context, any ontology of scientific change is essentially an attempt to answer three related questions:

1. What types of epistemic elements can epistemic agents take stances on?

2. What types of epistemic agents can take stances on epistemic elements?

3. What types of epistemic stances can epistemic agents take towards epistemic elements?
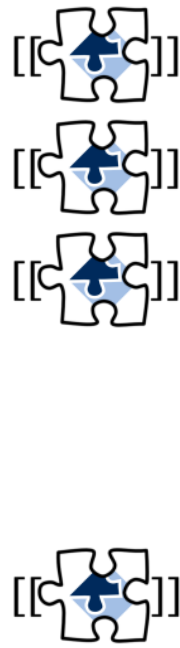

As of August 2018, the ontology of epistemic elements includes two types of elements that undergo scientific change - theories and methods of their evaluation (Barseghyan, 2015, pp. 3-11). The ontology of epistemic agents is limited to epistemic communities (Barseghyan, 2015, pp. 43-52; Overgaard, 2017). As for the ontology of epistemic stances, it is accepted nowadays that theories can be accepted/unaccepted, used/unused, and/or pursued/neglected, while methods can be employed/unemployed (Barseghyan, 2015, pp. 30-42; Sebastien, 2016; Barseghyan \& Shaw, 2017).

However, it becomes increasingly apparent that a new ontology of scientific change is in order. Specifically, recent developments in theoretical scientonomy as well as a reflection on the actual practice of the Encyclopedia of Scientonomy all suggest that the ontology of epistemic elements needs to be redrafted. First, William Rawleigh has recently suggested that questions/topics are to be accepted into the ontology of scientific change as a separate epistemic element (Rawleigh, 2018). This suggestion is backed up by strong theoretical arguments and, importantly, also reflects the actual practice of the Encyclopedia of Scientonomy where the category of topic/question along with the category of theory plays a central structural role. In addition, recent brainstorming sessions with Nicholas Overgaard, Paul Patton, and Gregory Rupik have made it transparent that methods of theory evaluation are, essentially, a subspecies of normative theories. Thus, it may be argued that, as epistemic elements, theories and methods are not completely distinct; this is another insight confirmed by our reflections on the practice of the Encyclopedia of Scientonomy.

Ideally, of course, it is the theoretical ontology that should guide and shape the encyclopedias and databases of a field. There must be good theoretical and empirical reasons for modifying the ontology of the field, i.e. reasons other than the fact that a certain ontological element was used in constructing a database or an encyclopedia. This much is understood. However, as scientonomy is dealing with historical agents taking epistemic stances towards epistemic elements, its ontology and laws should also apply to the mosaic of the scientonomy community itself. The Encyclopedia of Scientonomy provides an invaluable insight into the mosaic of an epistemic community - the community of scientonomists. Thus, if a certain ontological element turns out to be indispensable for constructing the encyclopedia, the question of the status of that element in the scientonomic ontology is worth pursuing: is that new element a mere practical instrument for organizing and storing data, or is it a distinct ontological element? While no encyclopedia or database can itself provide an unequivocal answer to this question and automatically alter the theoretical ontology of our field, the very fact that we couldn't do without the category of topic/question while building our encyclopedia suggests that we should have a thorough
Any discrepancy between the theoretical ontology of a field and what is meant to be its practical application is disturbing and calls for bridging the gap between the two. A good analogy is with the role of computer modeling in theoretical science. Often the mere act of designing a computer model (for example, of the posited mechanism for a cognitive process) forces one to think clearly and precisely about the posited mechanism being modeled. The Encyclopedia of Scientonomy (and the categories it uses) plays a similar role for scientonomy. 
theoretical discussion of the status of topics/questions in scientonomic ontology. The same goes for any discrepancy between the ontology of the encyclopedia and the theoretical ontology of scientonomy.

The main task of this paper is to redraft the scientonomic ontology of epistemic elements. I will start by reflecting on the practice of the Encyclopedia of Scientonomy and will highlight some of the key discrepancies between the ontology of scientific change currently accepted in theoretical scientonomy and the ontology which is at the backbone of the encyclopedia - the discrepancies that ideally should be eliminated. I will then suggest a new ontology of epistemic elements - an ontology which makes more sense from a theoretical perspective and simultaneously better reflects the actual practice of the encyclopedia. This discussion will shed new light not only on the status of methods as a species of normative propositions, but also on normative propositions in general. I will also suggest a reconceptualization of one of the central distinctions currently accepted in scientonomy - that between methods and methodologies. First, I will argue that the difference between the two is not ontological, as they both are essentially rules for theory evaluation, but practical or historical and concerns their respective employment and acceptance by different epistemic agents at different times. Second, I will show that the distinction between the two cannot be drawn along the lines of implicit and explicit. Additionally, I will suggest that definitions are to be included into the ontology as a distinct subtype of theory. Finally, I will offer a new definition of scientific mosaic that fits the new ontology.

\section{What's Wrong with the Current Ontology?}

According to the original scientonomic ontology suggested in The Laws of Scientific Change (Barseghyan, 2015), the two types of epistemic elements that undergo scientific change are theories and methods. While theory was defined as a set of propositions that attempt to describe something, method was defined as a set of requirements for employment in theory assessment:

\begin{tabular}{|c|}
\hline Theory $\equiv$ \\
\hline $\begin{array}{r}\text { A set of propositions that attempt to } \\
\text { describe something. }\end{array}$ \\
\hline
\end{tabular}

\begin{tabular}{|c|}
\hline Method $\equiv$ \\
\hline $\begin{array}{c}\text { A set of requirements for } \\
\text { employment in theory assessment. }\end{array}$ \\
\hline
\end{tabular}

When Sebastien's solution to the paradox of normative propositions and her new formulation of the third law became accepted in early 2017 (Sebastien, 2016), the scientonomic ontology of epistemic elements was changed to reflect the fact that normative theories, such as ethical norms, aesthetic principles, or methodological dicta, can also be part of a mosaic. These changes brought us to the following hierarchy of subclasses of theory:

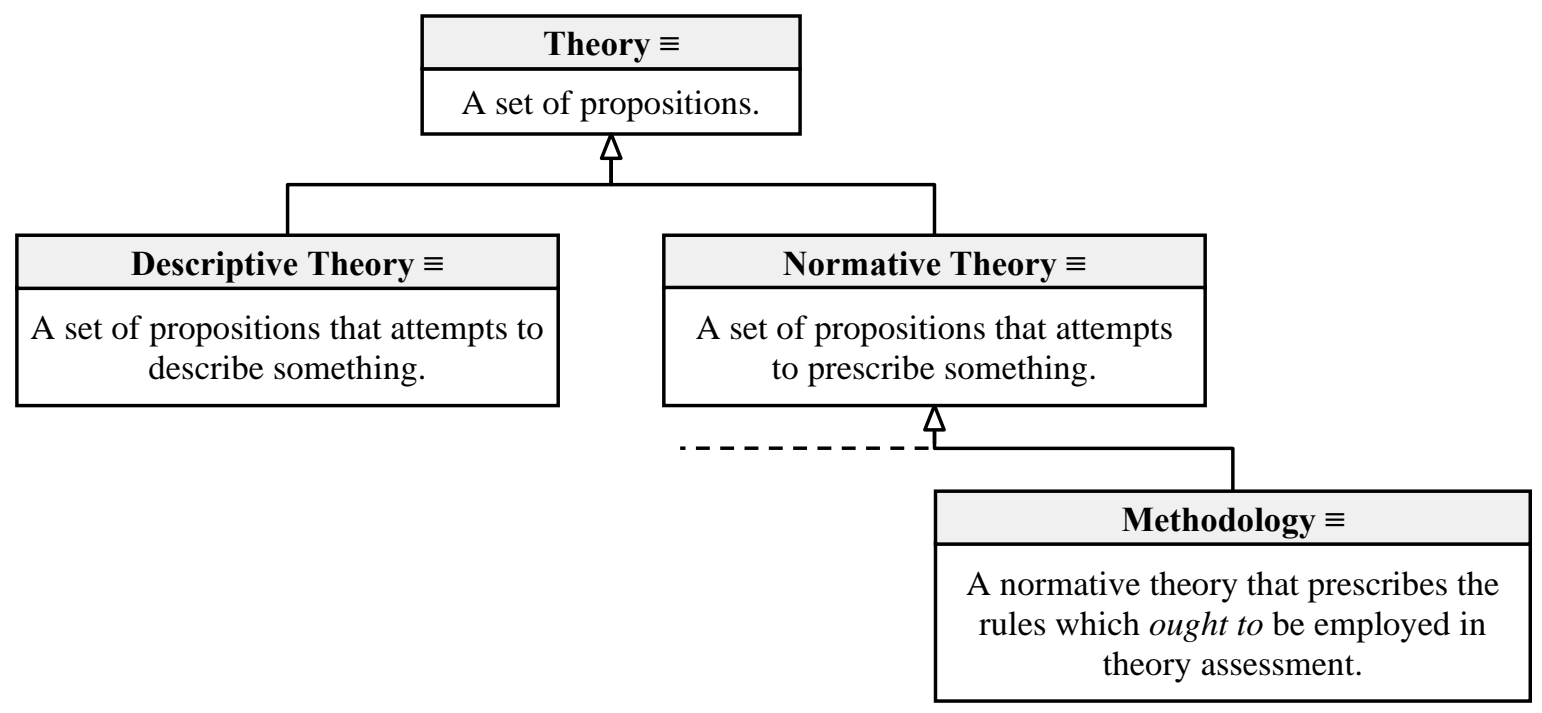


In addition, it has been argued by Rawleigh that questions too are to be accepted into the ontology of scientific change as a separate epistemic element (Rawleigh, 2018). Question is defined as a topic of inquiry and is essentially synonymous with problem, issue, and topic:

\section{Question $\equiv$ \\ A topic of inquiry.}

Rawleigh showed convincingly that not only our answers to question, i.e. our theories, change through time but also our questions: a question that is accepted as a legitimate topic of inquiry at one time-period can cease to be accepted as legitimate at another time-period and vice versa. Consider, for instance, the question concerning the distance between the centre of the universe and the sphere of stars that was accepted up until the $17^{\text {th }}$ century. Or consider the question of how biological species evolve through time that is accepted as a legitimate topic of inquiry nowadays but would not have been accepted in the $17^{\text {th }}$ century. As we still lack a law of question acceptance, the actual dynamics of how questions become accepted as legitimate topics of inquiry and how they cease to be accepted is currently unclear. What is clear, however, is that questions should be accepted as an indispensable element of the ontology of scientific change.

Rawleigh's modification clearly reduces the gap between the ontology of theoretical scientonomy and that of the encyclopedia. Indeed, consider the fragment of the encyclopedia's ontology concerning the categories of topic and theory:

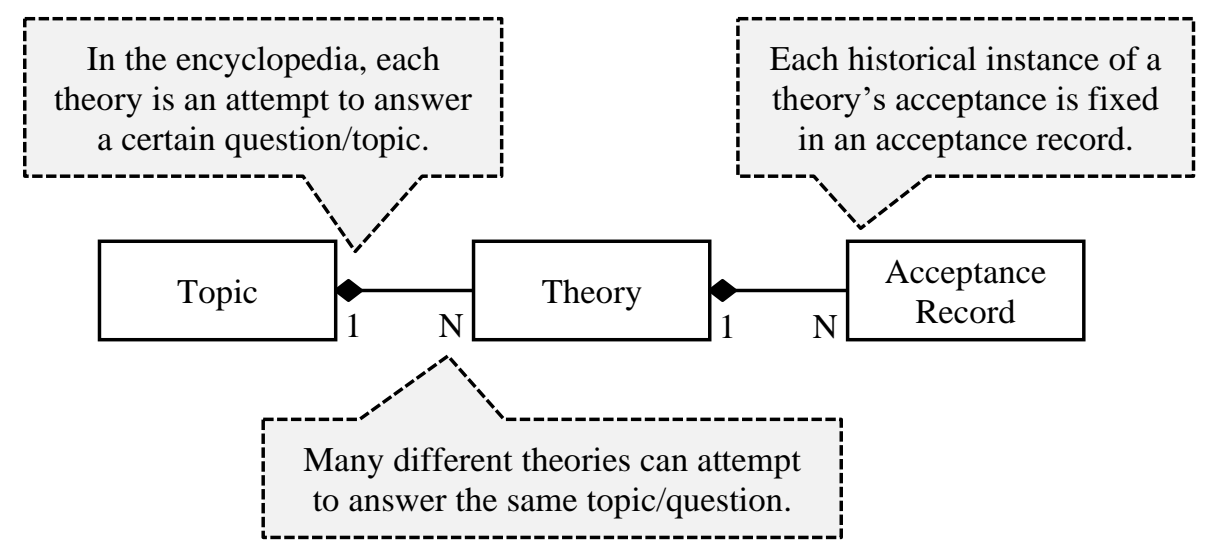

Thus, theories are taken as answers to certain questions/topics and each question/topic can have any number of possible answers/theories. All the known cases of a theory's acceptance by a certain epistemic agent are stated in respective acceptance records, which indicate the agent, the time-period when the theory was accepted, as well as state the indicators of acceptance and rejection. It is safe to say that this diagram properly reflects how the scientonomic data is currently stored in the database of the encyclopedia. The relation depicted on the diagram holds for all types of theories, including not only descriptive but also normative topics and theories:

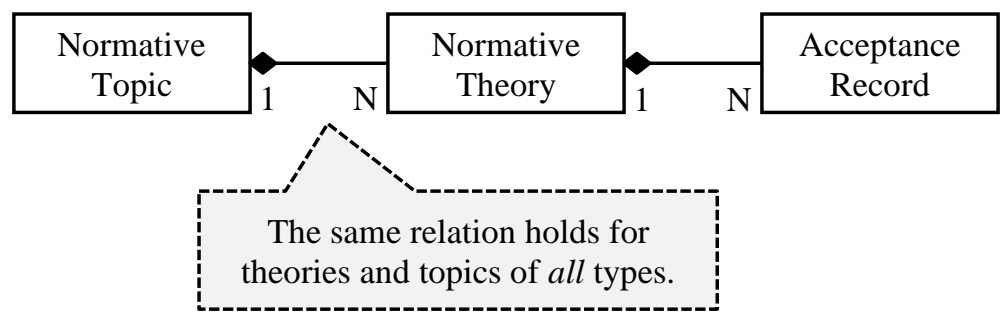

One question that has arisen in the context of the encyclopedia is how to store methods. We know how to store theories; they are entered as answers to questions. That much is clear. But how do we store different methods 
of theory evaluation? While this is an important practical question stemming from the need to document different methods in the encyclopedia, it also has important theoretical repercussions.

Let's first appreciate that there might be several competing methods that provide different criteria for evaluating theories of a certain kind. Consider, for instance, different drug testing methods employed at different times (Barseghyan, 2015, pp. 134-142) or different methods for evaluating general theories of natural philosophy/physics such as the Aristotelian-medieval method of intuition schooled by experience or the hypothetico-deductive method (Barseghyan, 2015, pp. 143-150). Since different competing methods can attempt to tell us how theories of a certain kind are to be evaluated, then each individual method is in fact an attempt to answer a certain question:

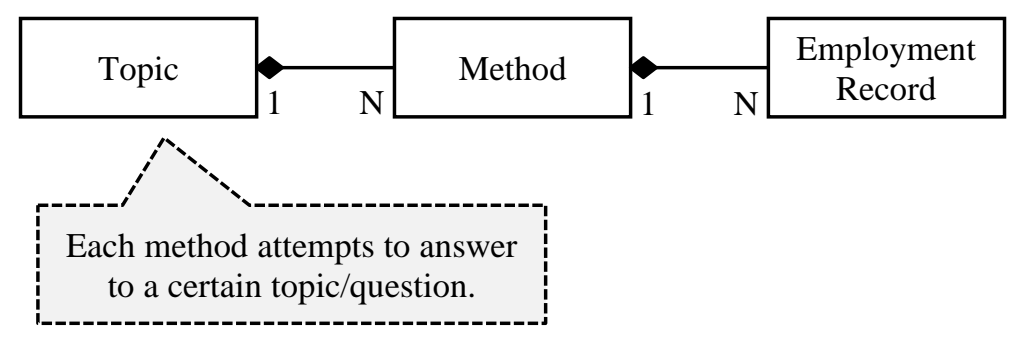

Now, this raises an important theoretical question: what type of a question does a method attempt to answer? By definition, methods provide criteria (requirements, rules) for theory evaluation, i.e. they tell us how theories of a certain kind ought to be assessed. As such, their propositional content is normative: when we explicate any given method, what we end up with is essentially a normative proposition (e.g. a hypothesis about a drug's efficacy is acceptable if the drug's effect has been confirmed in a blind trial, astronomical data is acceptable if it is obtained by means of a properly functioning telescope, etc.). It follows, therefore, that methods are attempts to answer normative questions. All drug testing methods are effectively attempts to answer the question "under which

Methods as norms are not to be confused with our contemporary claims that such-and-such a method was employed at a certain time period. The latter are essentially descriptive historical propositions of the form "method $x$ was employed by agent $y$ at time $z$ ". The distinction between the normative propositional content of the method and its historical fate is discussed below. conditions should a drug's therapeutic efficacy be accepted?". A similar picture holds for all methods. If we consider some of the most abstract methods, such as the hypothetico-deductive method, or the Aristotelianmedieval method of intuition schooled by experience, they both can be taken as attempts to provide an answer to the question "under what conditions should a theory be accepted as the best available description of its domain?". The same holds not only for criteria of theory acceptance but also for criteria of demarcation and criteria of compatibility (Barseghyan, 2015, pp. 9-11). Thus, any method attempting to provide some criteria for demarcating scientific and unscientific theories is essentially an answer to the question "when ought a theory to be considered scientific?". By the same token, any specific criterion of compatibility is an answer to the question "when is it permissible to consider two theories as compatible?". In short, any method can be considered as an attempt to answer a certain normative question concerning the evaluation of theories of a certain kind. Thus, we arrive at the following diagram:

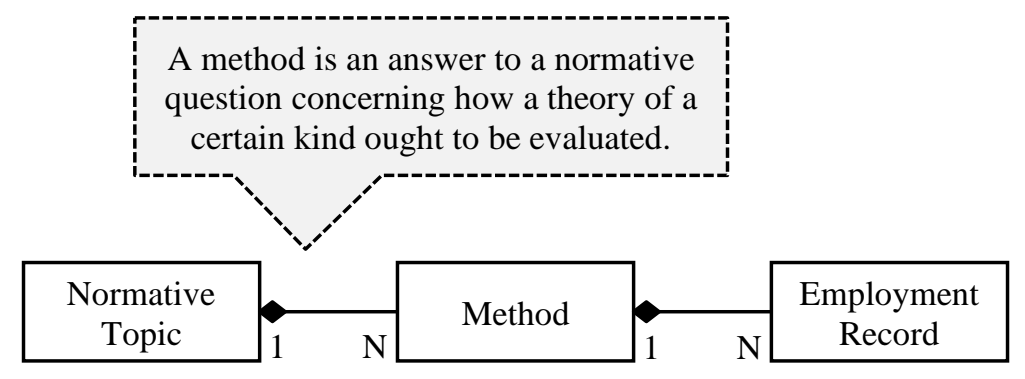


But if methods are answers to normative questions, then aren't methods themselves normative propositions? Indeed, they are! Since any method is an attempt to answer a certain normative question, therefore, any method can be expressed as a set of normative propositions (e.g. "a hypothesis on drug's efficacy is acceptable if...", "astronomical data is acceptable if...", "two theories from distinct domains are compatible if...", "a sociological theory is scientific if..."). This means that from the perspective of its propositional content, method is a very special subtype of normative theory:

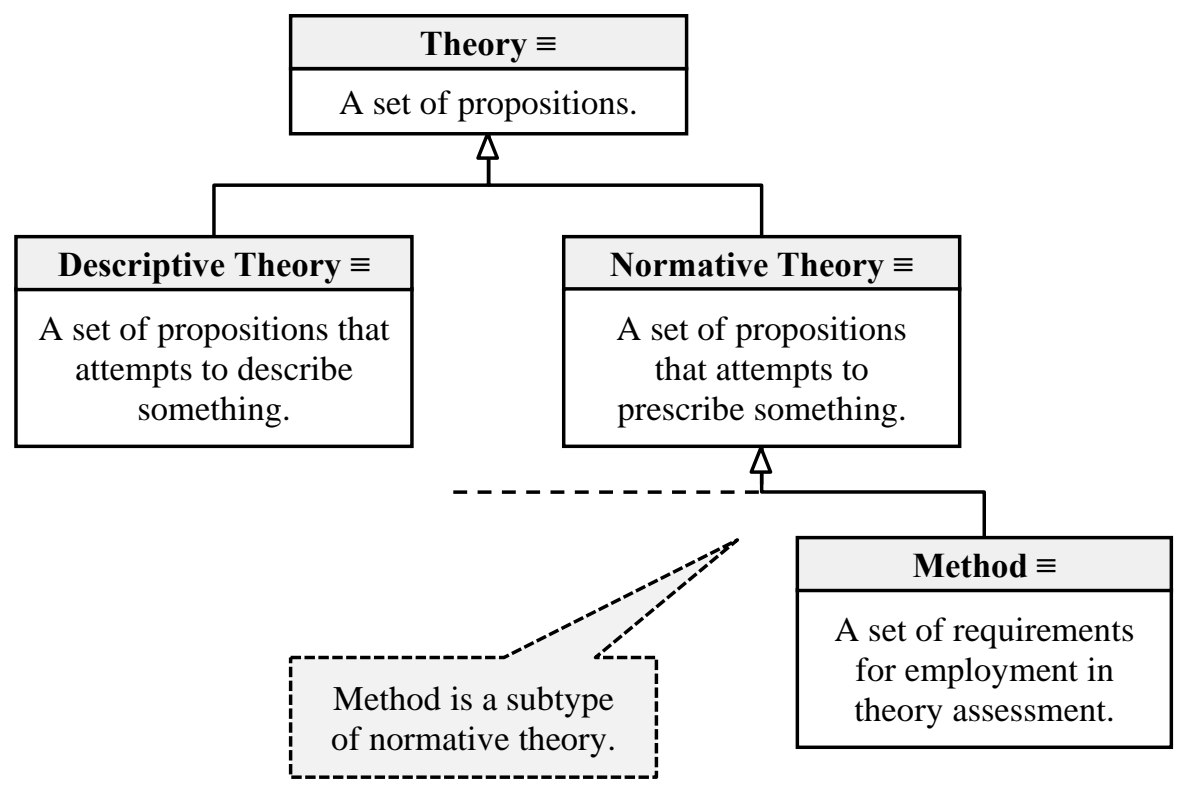

This surprising finding also makes apparent that, once written down, methods are indistinguishable from what we have previously labeled as "methodology" (Barseghyan, 2015, pp. 52-61). The key difference between the two concepts is not in their respective propositional contents, for both can be expressed as sets of normative propositions, but in their specific roles in the process of scientific change. What we have traditionally called "method" can become employed in theory evaluation, while what has been labeled as "methodology" can become accepted as the way theory evaluation ought to be done. While the distinction between the actual employment of certain rules and their acceptance as the correct way of doing science is still very important, it is also clear that in both cases we are dealing with normative propositions, i.e. rules for theory evaluation, which is, ironically, exactly what is stated in the original definitions of method and methodology (Barseghyan, 2015, p. 53). In other words, the key difference between what we have so far called "method" and "methodology" was thought to be their respective historical fates - methods have been understood as the rules that could become employed, while methodologies have been understood as the rules that could become accepted. But this difference shouldn't preclude us from seeing that the two are essentially normative propositions, i.e. criteria (rules, requirements, standards) for theory evaluation. Whether these criteria have been historically accepted as the correct way of doing science and found their way into the textbooks and encyclopedias or whether they managed to become the actual expectations of a certain epistemic agent and employed in theory assessment - in both cases, we are still dealing with criteria for theory evaluation. Therefore, we need to reconceive our notions of method and methodology.

There is another reason to believe that a new scientonomic ontology is in order. Traditionally, the difference between method and methodology, has been stated in terms of implicit and explicit. Method has been understood as a set of rules that can become the implicit expectations of a certain epistemic community, whereas the current definition of methodology is "a set of explicitly formulated rules of theory assessment" (Barseghyan, 2015, p. 53). Yet, the fact that employed rules are often implicit while accepted rules are often explicitly formulated shouldn't confuse us. After all the content of a proposition has nothing to with whether it is explicitly stated or only tacitly assumed. Thus, the fact that a theory has or hasn't been explicitly stated by a certain epistemic agent pertains to 
the theory's historical fate but does not change the theory's propositional content. Naturally, it won't occur to us to separate two distinct non-overlapping classes of implicit theories vs. explicit theories, for a theory can easily migrate from implicitly accepted to explicitly accepted and vice versa. What is accepted explicitly by one epistemic agent, may be accepted implicitly by another agent. But then, if the supposed difference between method and methodology is that the former is implicit, and the latter is explicit, then why should we separate them into two different classes in the first place?

One final indication that all is not well with our current scientonomic ontology is the fact that methodology itself currently has two different definitions. On the one hand, methodology is understood as a normative theory that prescribes the rules which ought to be employed in theory assessment (Sebastien, 2016, pp. 6-7). On the other hand, methodology is also understood as a field of study, as a normative discipline that formulates the rules which ought to be employed in theory assessment (Barseghyan, 2015, p. 13). This underappreciated ambiguity has its source in The Laws of Scientific Change, where methodology was given two distinct definitions (Barseghyan, 2015, pp. 13 and 53). It is true that, so far, this ambiguity hasn't caused much trouble within scientonomic discourse - mostly due to the fact that the two definitions are virtually never used in the same context. When contrasting methodologies with methods, methodology is normally taken to denote the openly prescribed rules that ought to be employed in theory assessment (e.g. Barseghyan, 2015, pp. 52-61). In contrast, when we juxtapose methodologies with general theories of scientific change, we understand methodology as a normative discipline that formulates the rules which ought to be employed in theory assessment (Barseghyan, 2015, pp. 12-21). So far, we have managed to avoid confusion since the two concepts of methodology have virtually never been used simultaneously. However, we have to be wary of this ambiguity as it can potentially create confusions.

In short, a redrafting of the scientonomic ontology is a task of vital necessity. The remainder of this paper is an attempt at such a redrafting.

\section{Method and Methodology, Employment and Acceptance}

The first step towards a new ontology of epistemic elements is to unite what has formerly been known as "method" and "methodology" into the same category of method, understood as a set of criteria (rules, requirements) for theory evaluation:

\begin{tabular}{|c|}
\hline Method $\equiv$ \\
\hline $\begin{array}{c}\text { A set of criteria for } \\
\text { theory evaluation. }\end{array}$ \\
\hline
\end{tabular}

Consequently, in this new ontology, the label "methodology" will be reserved exclusively for the respective normative discipline:

\section{Methodology $\equiv$}

A normative discipline that formulates the rules which ought to be employed in theory assessment.

This ensures that there is no longer any ambiguity concerning which of the two meanings of methodology - a set of openly prescribed rules or a field of study - we are referring to. If this new ontology is accepted, then methodology - just like most other "-logies" - will only denote the respective field of study.

As for the notion of method, it will include any criteria of theory evaluation regardless of whether they are accepted as the right prescriptions of how science ought to be done or whether they are actually employed in theory evaluation. Thus, a method can be both said to be accepted and employed. 


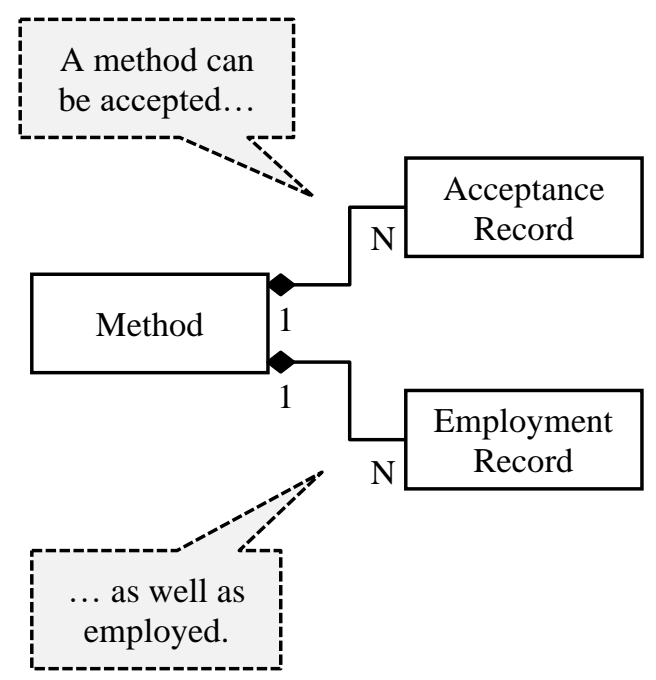

In this new ontology, we can now rightfully speak of, say, the double-blind trial method which can be both accepted by an epistemic agent as the correct way of testing a drug's efficacy and employed by that agent in actual drug testing. Similarly, we can think of cases when accepted and employed methods do not coincide. Take,

Note that, as usual, all historical examples considered in this theoretical discussion are for illustration purposes only; they are not to be taken as historical hypotheses on the status of different theories and methods at different period of time.

for instance, the $18^{\text {th }}$ century natural philosophy where the requirement to stay away from hypothetical entities was part of the accepted method. However, it is very unlikely that this requirement was actually employed at the time, since many of the then-accepted theories postulated the existence of such hypothetical entities (Laudan, 1984, pp. 57-59, 81-82). In contrast, the employed method of the time most likely contained the requirement of confirmed novel predictions which was not part of the accepted method (Barseghyan, 2015, pp. 145-150). Finally, we can conceive of methods which are neither accepted nor employed; consider, for example, a utopian method that states "a theory is acceptable only if it explains all the phenomena observed until present and provides absolutely correct predictions of all future events". In any event, it is important to separate the propositional content of a method from its historical record. It's one thing which rules are prescribed by a method and it's another thing which epistemic agents have historically accepted these rules as the right way of evaluating theories and/or employed these rules in actual theory evaluation.

Conveniently, this also solves the technical problem of how methods are to be entered and stored in databases and encyclopedias. A method and its historical track record should be entered in the following sequence:

1. The normative question which the method attempts to answer should be entered first.

2. Then the method has to be entered with all its criteria as an answer to that normative question. The method is to be entered separately from its historical track records, i.e. irrespective of which stances have been historically taken by different epistemic agents towards the method.

3. Each case when we believe the method was accepted by an epistemic agent as the right way of evaluating theories should be entered as a separate historical record that indicates the agent that accepted the method, the start and end of the acceptance period, as well as other relevant historical details. This acceptance record roughly corresponds to what was formerly known as openly prescribed methodology.

4. Each case when we believe the method constituted actual expectations of an epistemic agent should be entered as a separate historical record. This employment record should include the respective agent, the start and end of the employment period, plus any other relevant historical data.

Suppose, for instance, we wanted to document a specific version of the hypothetico-deductive method of theory evaluation. We would first have to enter the question

It is worth noting that, to the best of our knowledge, the actual employment of a method, unlike its acceptance, cannot be known directly, but can only be inferred by studying numerous instances of theory assessment during a certain period (by the second law) and checking whether it followed deductively from the accepted theories of the time (by the third law). Thus, it is likely that reaching precision in our method employment records will be a much more challenging task. 
which it attempts to answer. Then the formulation of the method itself would have to be entered in the form of "an empirical theory is acceptable only if...". Then, we would have to record all the known periods when the method has been accepted by different epistemic agents as the way in which theories ought to be evaluated, as well as all periods when the method has constituted the actual expectations of (i.e. employed by) a certain epistemic agent. If our current understanding of the history of the HD method is correct, then we would probably have records similar to the ones below:

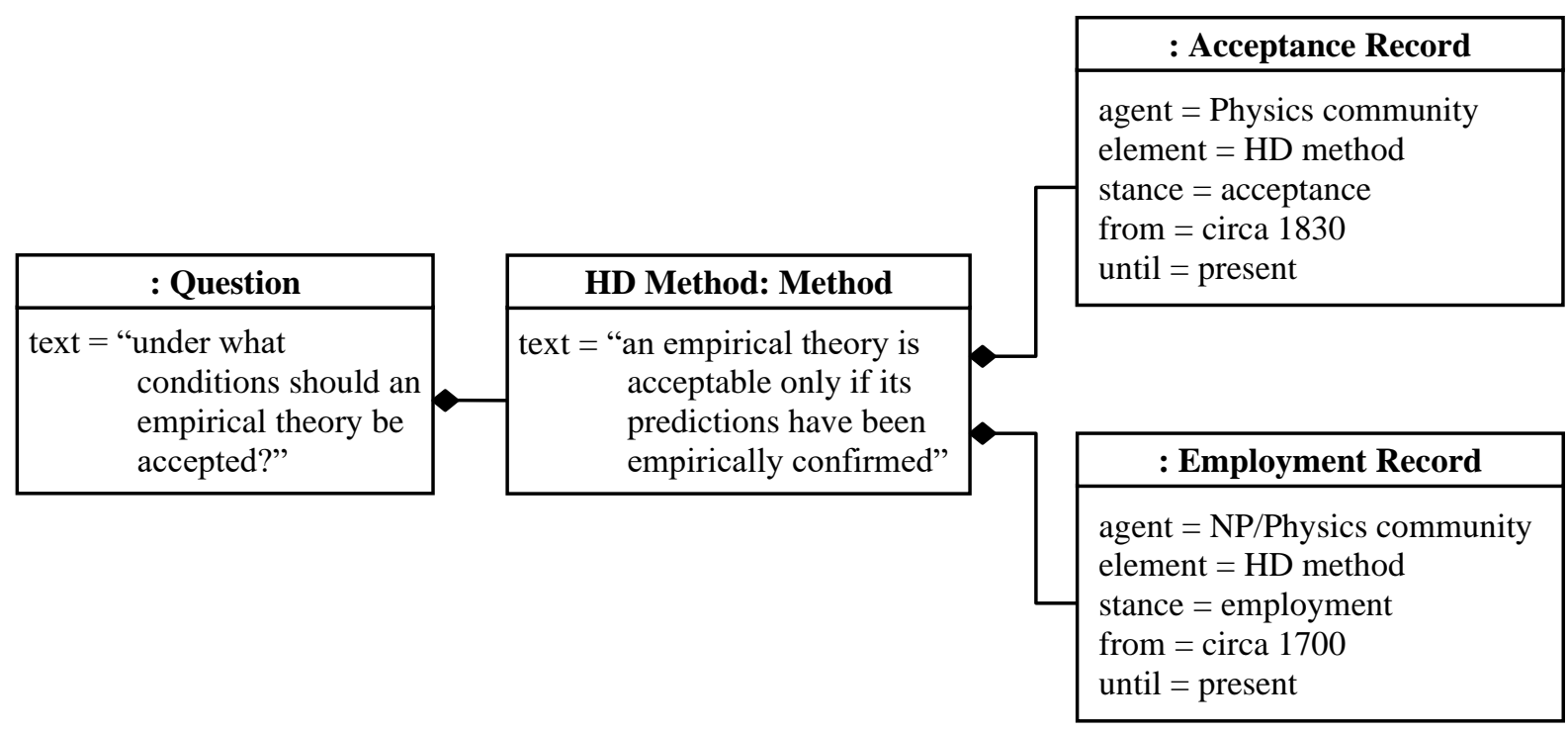

The precise formulations of the requirements of the HD method or the question it attempts to answer is obviously not my goal here. Similarly, I am not suggesting any historical hypothesis on when and how this method was accepted and/or employed. I am merely using these examples to illustrate a purely theoretical point: the propositional content of a method stays the same regardless of whether it has ever been accepted/unaccepted or employed/unemployed and, therefore, we need to clearly delineate the propositional content of a method from the historical records of its acceptances and employments by different epistemic agents.

Needless to say, both acceptance records and employment records are historical records, i.e. descriptive historical propositions attempting to describe a stance of a certain epistemic agent towards a certain epistemic element (in this case, a method) during a certain period of time. This also applies to any record of any other stance that may one day become considered of scientonomic interest (e.g. pursuit record, use record, etc.).

\section{Normative Theory, Method, Employment}

An important theoretical question arises in this context. Since methods have both the capacity of being accepted and the capacity of being employed, while theories in general don't have the capacity of being employed, then where in the hierarchy of the subtypes of theory does the capacity of being employed first emerge? In other words, is this something peculiar to methods only, or can we say that all normative theories have the capacity of being not only accepted but also employed? Thus, there are two distinct possibilities here.

Note that this discussion doesn't concern other epistemic stances, such as pursuit or use (Barseghyan, 2015, pp. 30-42; Barseghyan \& Shaw, 2017) but focuses exclusively on acceptance and employment.
In the first scenario, only methods have the capacity of being employed, while other theories can only be accepted. That is, in this scenario, employment as a stance can be taken only towards methods: 


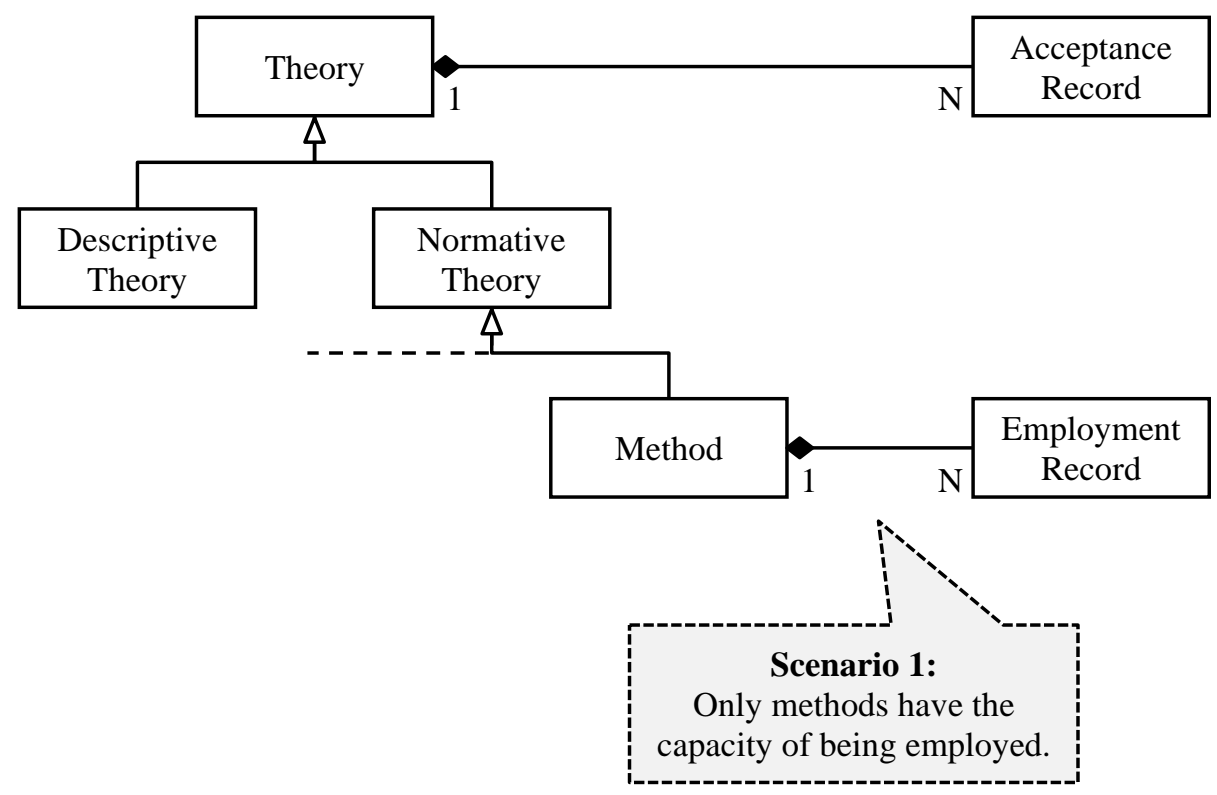

In the second scenario, all normative theories - including ethical norms, aesthetic norms, and methods - have the capacity of being employed, i.e. the stance of employment can in principle be taken towards normative theories of all types:

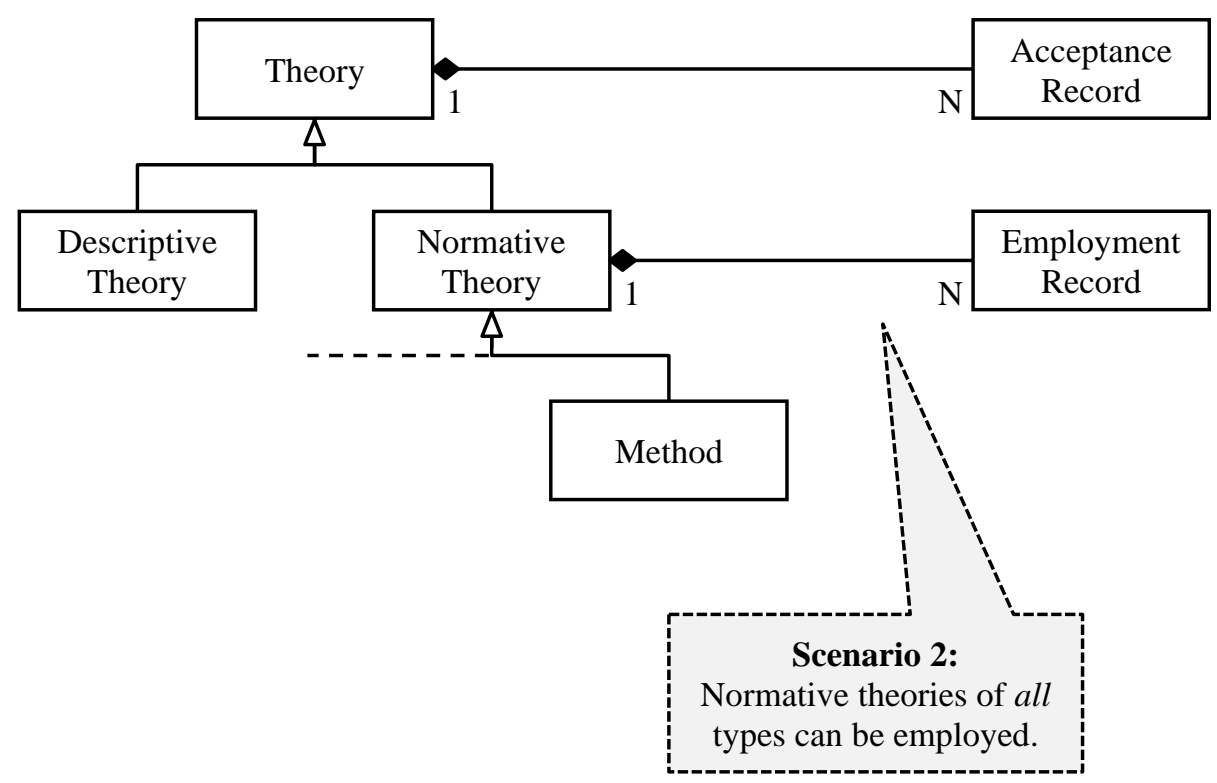

Now, which of these two options holds water? Is the stance of employment applicable to all types of norms or to methods only? It seems reasonable to suggest that the capacity of being employed and not merely accepted characterizes not only methods but all normative propositions, including those of ethics. After all, it's one thing to accept that killing is bad, it's another thing to act upon this norm (i.e. employ it) in practice. Likewise, accepting the principle of racial equality is one thing, employing it in practice is another thing (see for instance, Dixon, Durrheim, \& Tredoux, 2007). The difference between accepting an ethical norm in theory and acting upon it (i.e. employing it) in practice has been recognized and well documented. As shown by a series of prominent studies, what people claim they ought to do is often very different from what they actually do (LaPiere, 1934; Wicker, 1969; for a discussion, see Bicchieri \& Muldoon, 2014 and references therein). Therefore, it is safe to say that the capacity to be employed is not exclusive to methods but characterizes all normative propositions.

One possible objection to this conclusion is that it is not quite clear what scientonomy has to do with the employment of ethical or aesthetic norms. The fact that a certain community at a certain time-period did or did 
not act in accord with a given ethical norm may be of great interest to historians, anthropologists, ethnographers, and other students of society and culture, but how, one may wonder, is it relevant to scientonomy? Unless it is shown that the employment of an ethical or aesthetic norm can affect the process of scientific change, one may argue, it is unclear how it can be of interest to scientonomy.

I find this line of reasoning unconvincing. Yes, scientonomy currently lacks an understanding of how ethical norms or norms in general affect the process of theory or method change. The role of ethical or aesthetic norms in the mechanism of scientific change is an open question. Yet, that question pertains to the dynamics of scientific

While the question of the role ethical norms in scientific change is beyond the scope of this paper, there seem to be prima facie reasons to suspect that such a role is plausible. For example, brain lesion studies in non-human animals have been quite helpful in illuminating the functional modularization of the nervous system (Grobstein, 1990). In principle, similar studies could also help elucidate the functional organization of language in humans, a matter of some interest to linguists and cognitive scientists (Chomsky, 2017). However, there are obvious ethical reasons why such studies have not been conducted. changes. In contrast, our current concern is not with the dynamics of scientific change but with its ontology. Thus, our current question is not whether the employment of ethical or aesthetic norms can have any effect on changes in scientific theories and methods, but whether norms in general can be employed in the first place. The answer to this latter question is unequivocally positive: the capacity of being employed and not merely accepted is a feature of all norms and is not exclusive to methods of theory evaluation. In short, it's one thing to accept the existence of a certain phenomenon; it's another thing to understand its dynamics.

In scientonomy, we have already accepted the existence of several entities and stances the dynamics of which we don't quite understand. Consider for instance, the epistemic stances of pursuit and use: we accept the existence of these stances without having any idea how these stances obtain and how they change through time. But then why should we suddenly reject the fact that norms can be employed simply because we don't understand what role this norm employment plays in the process of scientific change? The same goes for accepting the existence of questions as a separate epistemic entity. Yes, we don't currently know how questions change through time and how their changes affect changes in theories and methods, but I don't see how it can stop us from accepting that questions are part of the ontology of scientific change. Surely, accepting the existence of an epistemic entity or a stance is the first step towards studying its dynamics. Therefore, I see no reason why we shouldn't accept that normative propositions can be both accepted and employed; we should accept this so that we can pose a meaningful question about the effects that the employment of ethical or aesthetic norms or normative propositions in general can have on the process of scientific change.

Once we accept that employment as an epistemic stance can be taken towards norms of all types, we have to modify the definition of employment accordingly. The current definition of the concept links it closely to methods (Patton, Overgaard, \& Barseghyan, 2017, pp. 34):

\section{Employed Method $\equiv$}

A method is said to be employed if its requirements constitute the actual expectations of the community.

Note an important difference in naming: our terms that denote epistemic stances towards theories are phrased as "theory acceptance", "theory use", and "theory pursuit", whereas there is currently no "method employment" as such. Instead, there is "employed method". While it is understood that the latter denotes the stance of employment, the current naming is inconsistent with the naming of other stances. Thus, I suggest we switch from "employed method" to "norm employment" and accept the following definition of the term:

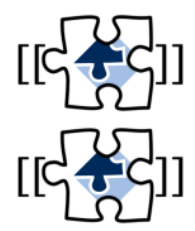




\begin{tabular}{|c|}
\hline Norm Employment $\equiv$ \\
\hline $\begin{array}{c}\text { A norm is said to be employed if its } \\
\text { requirements constitute the actual } \\
\text { expectations of an epistemic agent. }\end{array}$ \\
\hline
\end{tabular}

This new definition serves two purposes. First, it reflects the fact that norms of all types can in principle be employed and, second, it makes the naming of the stance consistent with the naming tradition of other epistemic stances in scientonomy.

\section{A Note on Normative Propositions}

Before we proceed with our redrafting of the ontology of scientific change, a general note on normative propositions is in order. There is a prominent debate on whether and how normative propositions can have a truth value. This important question concerns the very foundations of the logic of normative propositions, deontic logic (Føllesdal \& Hilpinen, 1971; McNamara, 2014). The question began to be widely discussed by philosophers in the 1930s during the heyday of logical positivism. The view on normative (evaluative, prescriptive) propositions accepted by many logical positivists was that since normative propositions don't attempt to describe anything, they cannot have any truth value, i.e. they cannot be either true or false (Stevenson, 1944; Ayer, 1949; for discussion, see Rutte, 1991). Now, by definition, logic is a set of rules for entailing some propositions from others. But the standard notion of logical entailment is only applicable to propositions that can have a truth value: to say that a conclusion is entailed by (follows from) certain premises amounts to saying that it is impossible for the conclusion to be false if the premises are true. This raises a question: how can there be any logic of normative propositions given that they don't have any truth value? Here is the argument:

(1) Normative propositions cannot be either true or false i.e. they don't have a truth value.

(2) Logic is a set of rules for entailing some propositions from others.

(3) A conclusion is said to be entailed by its premises if and only if the conclusion cannot be false when the premises are true.

(4) It follows from (1), (2), and (3) that there can be no logic of normative propositions, i.e. no deontic logic.

If we were to accept the standard notions of entailment and logic and also agreed with logical positivists that normative propositions cannot have any truth value, then we would have to accept that the very idea of deontic logic is misguided.

However, there seem to be clear-cut cases of valid reasoning with normative propositions, such as:

Premise 1: We ought not to kill human beings.

Premise 2: Socrates is a human being.

Conclusion: We ought not to kill Socrates.

Thus, we are facing a choice: either we should change some of our fundamental assumptions about normative propositions, logic, or entailment to accommodate for the possibility of deontic logic, or alternatively we should accept that there can be no deontic logic whatsoever. This is the gist of the so called Jørgensen's dilemma, named after Jørgen Jørgensen who formulated it in 1937 (Jørgensen, 1937; for discussion, see Volpe, 1999; Hilpinen, 2006; McNamara, 2014).

There are several opposing approaches to Jørgensen's dilemma, ranging from attempts to interpret normative propositions as somehow expressible through (reducible to) descriptive propositions (e.g. Dubislav, 1937, Jørgensen, 1937; von Wright, 1963) to attempts at widening the notion of logical entailment in such a way as to 
avoid referring to the truth/falsity of propositions (Grue-Sörensen, 1939; Hofstadter \& McKinsey, 1939; Alchourrón \& Martino, 1990). While there is currently no agreement among philosophers and logicians as to how Jørgensen's dilemma is to be solved, it is safe to say that it hasn't precluded the development of deontic logic itself.

Clearly, the solution of Jørgensen's dilemma can have important implications for the scientonomic ontology of epistemic elements. If, for instance, it turns out that normative propositions are somehow reducible to (expressible through) descriptive propositions, then we will have to change our basic taxonomy of subtypes of theory and accept that normative propositions are a subtype of descriptive propositions.

As for the question of whether normative propositions can or cannot have a truth value, it has no direct bearing on our scientonomic discourse. What matters from the scientonomic perspective is not whether normative propositions can or cannot be true or false, but whether epistemic agents can take epistemic stances towards them, i.e. whether they can be employed, accepted, etc. So regardless of our personal views on whether normative propositions can have a truth value, we can all agree on the following two points:

1. It is the case that normative propositions can be and often are accepted/unaccepted by epistemic agents. Consider, for instance, our current belief that all humans ought to be treated equally regardless of their race, nationality, ethnicity, etc.

2. It is the case that normative propositions can be and often are employed/unemployed by epistemic agents as norms that actually guide their choices and actions. Consider, for example, the rule that humans ought to help each other in emergencies. Regardless of whether we do or do not accept this norm, many of us clearly act upon it.

Evidently, neither of these two points assume that normative propositions can have a truth value. Our belief that normative propositions can be both accepted and employed is impartial to the question of truth/falsity of normative propositions.

\section{Explicit \& Implicit}

In section Explicit and Implicit of The Laws of Scientific Change, a distinction is drawn between methods and methodologies (Barseghyan, 2015, pp. 52-61). According to that distinction, methods are understood as the actual - often tacit/implicit - expectations of a certain agent, while methodologies are always openly/explicitly stated by a certain epistemic agent as the right way of theory evaluation (Barseghyan, 2015, pp. 53-54). Now, it follows from the previous discussion that this characterization of methodologies as explicitly stated rules and methods as often implicitly employed rules is misleading.

First, it must be appreciated that whether a rule has or hasn't been explicitly stated has to do with contingent historical circumstances and says nothing about the propositional content of the rule. Thus, the propositional content of the rule "astronomical data is acceptable only if it has been obtained by a healthy human eye" stays

It is important to distinguish between ontological and methodological questions. When we ask what types of epistemic elements are out there and what types of stances can be taken towards them by epistemic agents, we are inquiring into the ontology of our domain. In contrast, when we ask how we can know that a certain stance was taken by a certain agent towards a certain epistemic element at a certain period, we are posing a methodological question. From the ontological perspective, there is no difference between the explicit and implicit acceptance of an element the element maintains its propositional content one way or the other. Yet, from the methodological perspective, there seem to be notable differences between how we identify cases of explicit acceptance and how we identify cases of implicit acceptance. In general, explicitly stated elements can be extracted more directly from historical sources, while implicit elements can only be inferred. This paper is concerned exclusively with the ontological questions. exactly the same regardless of whether, when, and by which epistemic agents it has or hasn't been explicitly stated. Whether a rule has been explicitly formulated at a certain time-period by a certain epistemic agent is itself a very interesting topic for observational scientonomy, but it concerns the historical records of acceptances and employments of that rule by different epistemic agents at different time-periods. Once again, it has zero effect on the propositional content of the rule in question. The new ontology of epistemic elements solves this problem by divorcing the notion of method from its historical record of acceptances and employments (see section Method and Methodology, Employment and Acceptance above). 
Second, it is clear that all propositions can be both explicit and implicit; that's not what characterizes them. Descriptive or normative, theory or method - every epistemic element has the capacity of being explicitly stated as well as the capacity of being tacitly implied. The same holds for epistemic stances. For example, a theory or a method can be accepted both openly and tacitly. Similarly, normative propositions can be employed both implicitly and explicitly. To appreciate this point, we have to first clarify what we mean by implicit and explicit.

Let us start by considering the traditional distinction between explicit and implicit. The tradition going back to Ryle and Polanyi defines explicit knowledge as that which the knower can make explicit by means of a verbal statement. Consequently, implicit or tacit knowledge is traditionally defined as that which the knower cannot make explicit by means of a verbal statement (Dummett, 1991; Davies, 2015). It is readily seen, however, that these definitions are not quite suitable for our discussion, as they have several flaws:

1. They don't distinguish between what hasn't been explicated and what cannot even in principle be explicated in a propositional form.

2. They focus on the agent's ability to explicate, rather than on the very fact of it being explicitly stated or tacitly assumed.

3. Many things that have never been openly formulated are rendered explicit by these definitions. For instance, they render my knowledge of $1347+721=2168$ explicit even before I bothered to do the math.

Thus, we need a different taxonomy. I believe that the three-fold distinction that Maxim Mirkin and I have recently suggested in another context (Barseghyan \& Mirkin, 2019) suits our purposes much better. According to our three-fold distinction, there are three distinct categories:

1. Explicit: propositional knowledge that has been openly formulated by an epistemic agent.

2. Explicable-implicit: propositional knowledge that hasn't been openly formulated by an epistemic agent.

3. Inexplicable: non-propositional knowledge, i.e. that which cannot even in principle be formulated as a set of propositions.

This three-fold distinction is much richer than the traditional two-fold distinction between explicit and tacit. While, explicable-implicit and inexplicable are both types of tacit/implicit knowledge, there is a crucial difference between the two, as the former is propositional, and the latter is non-propositional. The table below summarizes the three-fold distinction:

\begin{tabular}{|c|c|c|}
\hline \multicolumn{3}{|c|}{ Can it be, in principle, formulated as a set of propositions? } \\
\hline \multicolumn{2}{|c|}{ Yes } & $\mathrm{No}$ \\
\hline \multicolumn{2}{|c|}{ Has it been openly formulated by the agent? } & \multirow{3}{*}{$\begin{array}{c}\text { Inexplicable: } \\
\text { Non-propositional } \\
\text { knowledge, i.e. } \\
\text { knowledge that cannot, } \\
\text { even in principle, be } \\
\text { formulated as a set of } \\
\text { propositions. }\end{array}$} \\
\hline Yes & No & \\
\hline $\begin{array}{c}\text { Explicit: } \\
\text { Propositional } \\
\text { knowledge that has } \\
\text { been openly formulated } \\
\text { by the agent. }\end{array}$ & $\begin{array}{l}\text { Explicable-Implicit: } \\
\text { Propositional } \\
\text { knowledge that hasn't } \\
\text { been openly formulated } \\
\text { by the agent. }\end{array}$ & \\
\hline Explicit & \multicolumn{2}{|c|}{ Tacit/Implicit } \\
\hline \multicolumn{2}{|c|}{ Propositional } & Non-Propositional \\
\hline
\end{tabular}

Whether there is such a thing as genuinely inexplicable (i.e. non-propositional) knowledge is a topic of debate that goes back to Gilbert Ryle (Ryle, 1949). While the so-called anti-intellectualists hold that there is genuine knowledge that cannot even in principle be expressed in propositions, intellectualist argue that all knowledge is in principle expressible through propositions after all (Polanyi, 1958; Stich, 1978; see Fantl, 2017 for discussion). 
It is important to appreciate that scientonomy is currently not equipped to deal with the category of inexplicable knowledge. The currently accepted definition of theory as a set of propositions (Sebastien, 2016) makes it clear that the scientonomic laws of scientific change apply exclusively to changes in those beliefs and norms that are explicable propositionally. It remains to be seen whether this feature of our current theoretical scientonomy is to be considered a virtue or a vice. In any event, it is the distinction between explicit and explicable-implicit that I will focus on here.

Evidently, all types of epistemic elements can be both explicit and explicable-implicit. This goes for theories of all types - both descriptive and normative, including methods and ethical norms. Consider, for example, the

It is conceivable that most implicit elements of an epistemic agent's mosaic are not very precise and can only be expressed in something as vague as "there's something wrong with this theory", "there seems to be something like dark matter out there", etc. Yet, however vague, these too have some propositional content. idea that particles have well-defined objective values of position and velocity even before they are measured. It is safe to say that this assumption was implicitly accepted by the physics community as part of classical physics long before it was explicitly formulated by Einstein in the

1930s as part of his criticism of quantum mechanics (Fine, 2017). Similarly, the possibility of arbitrarily large velocities was implicitly accepted by physicists long before it was made explicit and eventually rejected with the acceptance of relativity theory (Goldhaber, 1975). Explicable-implicit and explicit theories can be found in all fields of inquiry:

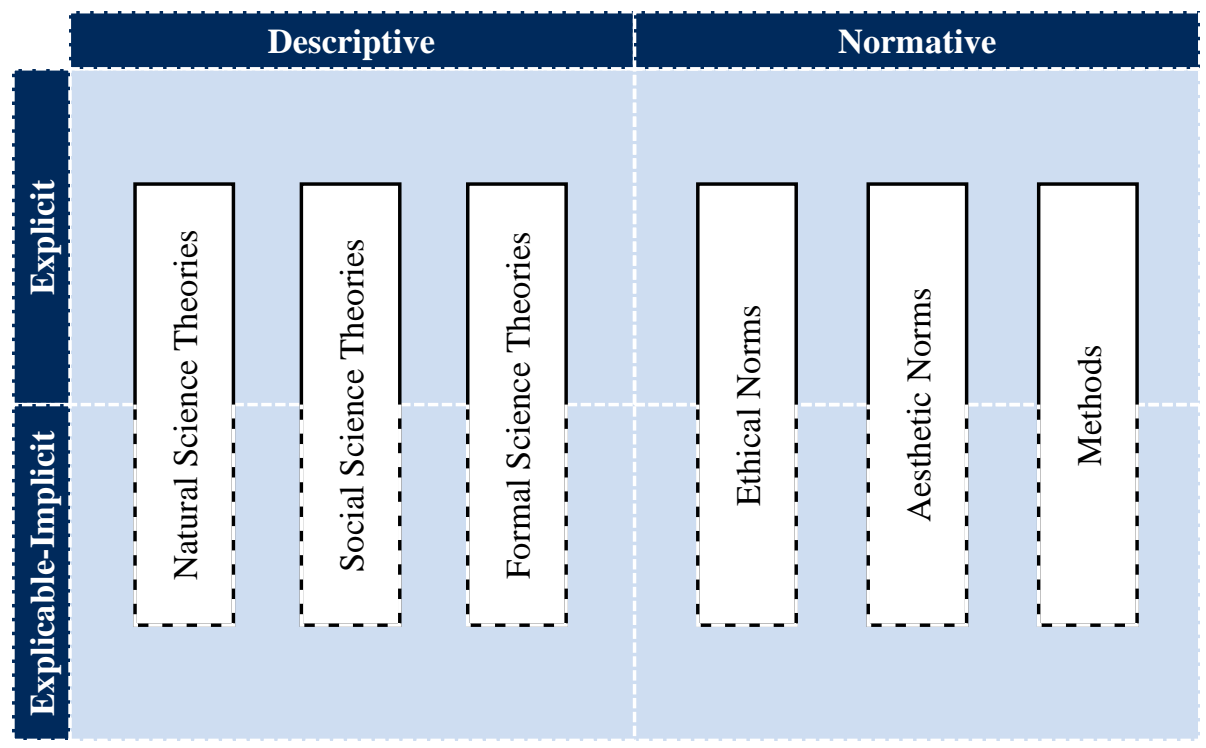

The same also goes for all questions: they can be explicitly stated or implicitly assumed. Take, for instance, our recent experience with the question of the ontology of scientific change. While the question has been implicitly accepted since the inception of scientonomy, we have only recently come to explicitly formulate it. Similarly, all epistemic stances too can be taken both explicitly and implicitly. Among other things, this means that both the

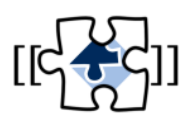
acceptance and employment of a norm can be both explicit and implicit. To appreciate this, consider two hypothetical scenarios.

First, imagine an idealized agent which explicitly accepts that all humans ought to be treated equally regardless of their race, ethnicity, nationality, religion, etc. Now, suppose for the sake of argument, that this agent starts to critically reflect on their own behavior and soon realizes that in fact they don't always treat all humans equally and that, unfortunately, sometimes they discriminate by race, ethnicity, nationality, religion, etc. Thus, this agent becomes aware that the norm they actually employ in practice is not the same as their accepted norm. Importantly, in this hypothetical scenario, both the accepted norm and the employed norm are explicitly stated. 
Now imagine a different agent who, in their actions, is always extremely respectful towards all people, regardless of how deserving or undeserving these people might be. In this case, we can rightfully claim that the agent employs (i.e. acts upon) the norm "one ought to treat everyone with respect" in their everyday practice. Let's also imagine that this agent has never explicitly stated any opinions on how one ought to treat others, nor have they ever reflected on their own behavior; in other words, this agent has no explicitly accepted or explicitly employed norms. Now suppose that, when asked, the agent says that they don't think that all people ought to be treated with respect. In fact, the agent accepts that one's respect towards people should be proportional to how deserving these people are. When told that their actual practice reveals a very different employed norm, the agent concedes that due to their natural kindness they end up treating everyone with utmost respect regardless of their merit, yet, they insist that this is not a right thing to do. What this hypothetical scenario shows is that it is possible for an agent to implicitly accept a norm which is very different form the norm they implicitly employ.

In short, both the acceptance and the employment of a norm can be both explicit and implicit. This holds for all norms, including methods that are accepted/employed by Once again it is important to keep in mind the difference between ontological and methodological questions. My claim here is purely ontological. i.e. it is possible for an agent's implicitly accepted norms to be quite different form their implicitly employed norms. There are important methodological questions that I do not address here: how we can know that a certain norm was implicitly accepted by an agent and how we can know that a norm was implicitly employed by an agent. There doesn't seem to be a simple answer to these methodological questions, which is not surprising. For example, what happens if the agent treats everyone with equal respect because of a cognitive deficit which prevents them from distinguishing one person from another? Can we still claim that they are still implicitly employing the norm? Or, what about any behavior that arises as an incidental side consequence of pursuing some other implicit goal? Suppose, an agent's implicit norm is to always behave so as to maximize their profit. As a result of their actions, harm to the natural environment typically results. Should it really be said that this agent's implicit norm is to destroy the environment, even though such harm often arises as an unintended and unconsidered side consequence of the actual employment of an implicit norm of profit? These important methodological questions call for a detailed study. an epistemic community:

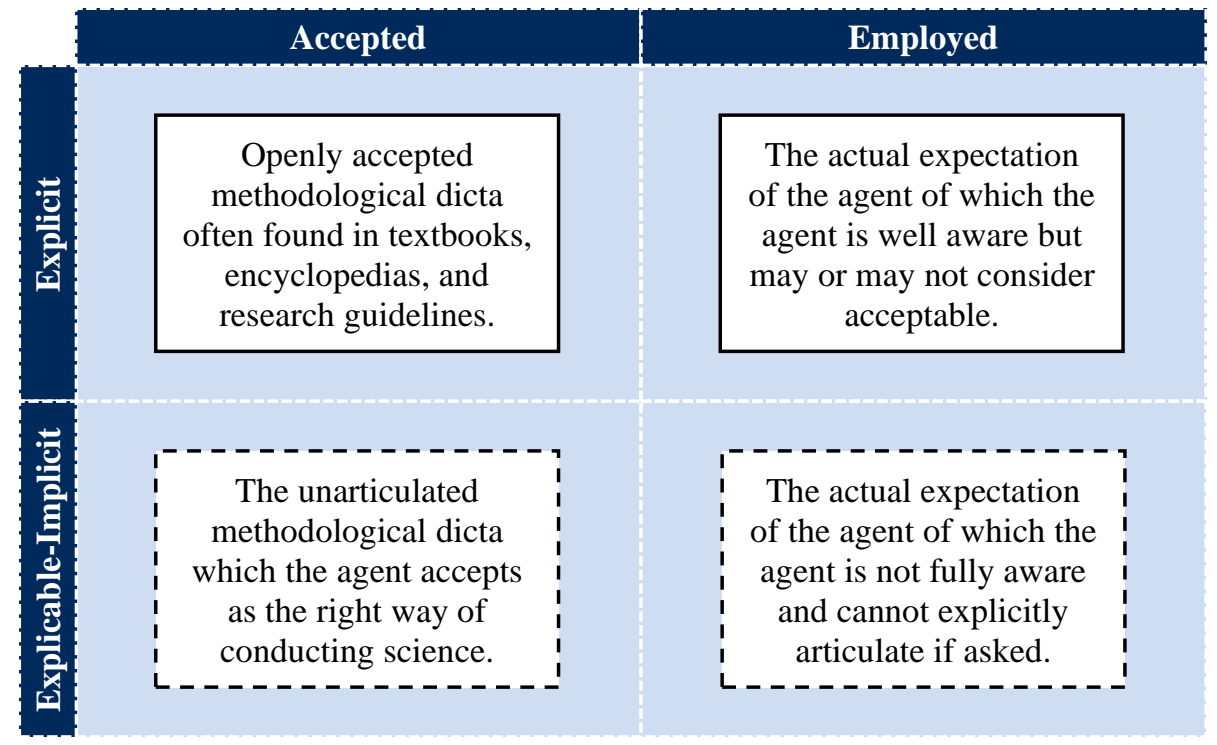

From the scientonomic perspective, the important distinction here is that between acceptance and employment, and not that between explicit and implicit. Thus, it should not come as a surprise that the current laws of scientific change do not discriminate between explicitly and implicitly accepted or between explicitly and implicitly employed, but equally apply to explicit and implicit alike. This only confirms that the distinction between explicit and implicit cannot be taken as grounds for differentiating distinct epistemic elements or distinct epistemic stances. That's why the currently accepted scientonomic notions of method and methodology are untenable and should be replaced by the ones suggested in this paper. 


\section{Definition}

While the introduction of questions into the scientonomic ontology of epistemic elements reduces the gap between our theoretical ontology and the ontology of the encyclopedia, it doesn't eliminate that gap. If we carefully consider the ontology of the encyclopedia, we notice that implicit in it is the idea that there are three subtypes of theory - descriptive theories, normative theories, and definitions. Descriptive theories are the ones that attempt to describe something. As usual, here descriptive is understood in the broad sense which includes all propositions that attempt to state how and/or why things are, were, or will be. Thus, the category of descriptive theory includes explanations, predictions, retrodictions, etc. In this context, it is contrasted with the category of normative theory, which includes propositions that attempt to prescribe and/or evaluate something. Finally, the ontology of the encyclopedia distinguishes descriptive and normative theories from definitions, which attempt to define a certain term. The following UML diagram depicts the encyclopedia's ontology of subtypes of theory:

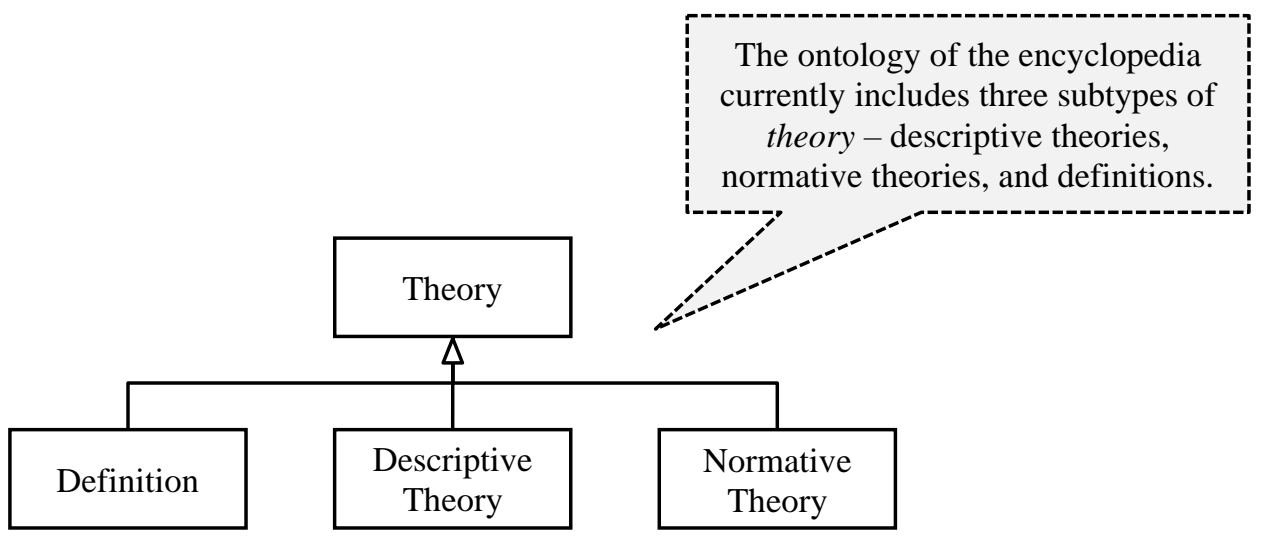

In contrast, definitions do not feature as a subtype of theory in the currently accepted ontology of theoretical scientonomy. The class of theory currently only includes descriptive and normative theories:

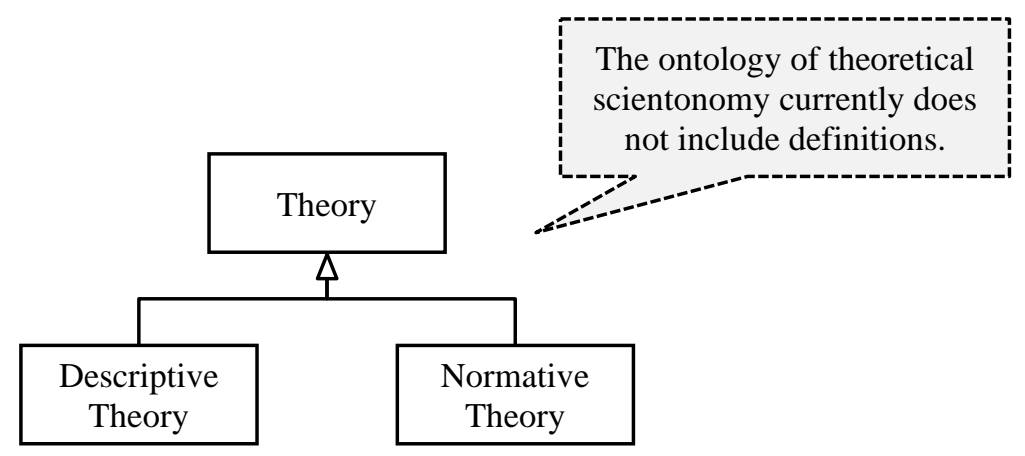

Clearly, something needs to be done to eliminate this discrepancy.

Unsurprisingly, there is a vast philosophical and logical literature concerning the nature and types of definitions (see Sager (Ed.), 2000; Gupta, 2015, and references therein). The central question that concerns us here is whether definitions are propositions, or whether they have no propositional content. This question has traditionally been discussed in the context of another question - that concerning the ability or inability of definitions to have a truth value (Weingartner, 1965). Those who believed that definitions are not propositions often arrived at this conclusion from the premise that definitions cannot be true or false. Ockham, Brentano, Peirce, as well as Whitehead and Russel all held that definitions are not propositions, since all propositions are either true or false, while we cannot speak of true or false definitions (Weingartner, 2000, pp. 45-47, 65). As such they opposed a tradition going back to Aristotle, which held that definitions can be true or false, and a true definition is the one that captures the essential qualities of its definiendum (Rey, 2000; Deslauriers, 2007). In general, those who believed that definitions are propositions also held that they can have a truth value. Thus, 
Thomas Aquinas, Mill, Frege, and Tarski all accepted that we can legitimately speak of a definitional proposition as being true or false (Weingartner, 2000, pp. 47-49). This view was also held by many logical positivists, including Carnap, who believed that definitions can be true, yet importantly not in the Aristotelian sense of correctly capturing the essential features of the definiendum, but in the sense of being true within a certain linguistic framework. In Carnap's own words, definitions are true "not on factual but on logical grounds, i.e. strictly on the basis of meaning" (Carnap, 1958, pp. 63-64). Since both parties shared a premise that all propositions have a truth value, they all agreed that in order to qualify as propositions definitions would be expected to have a truth value.

While the question of whether definitions are propositions has been traditionally reduced to the question of whether definitions can have a truth value, such a reduction is by no means inevitable. For instance, some authors have held that definitions are propositions, despite the fact that they do not have or cannot have a truth value. Thus, Macagno and Walton say that "definitions are propositions which do not need to be true" (Macagno \& Walton, 2010, p. 20). Effectively they deny the traditional premise that all propositions have a truth value.

Although the question of whether definitions can have a truth value is of great interest to epistemology, we must appreciate that that the question of scientonomic interest is different. Just as in the case of normative propositions, our goal here is not to determine whether definitions can be true or false, but to find out whether they can be accepted or unaccepted by an epistemic agent. As far as the ability to be accepted is concerned, the answer is clear - definitions can be and have been accepted by epistemic agents. In fact, it is safe to say that any mosaic of any epistemic agent will necessarily include some definitions of terms, for without such definitions implicit or explicit - no descriptive or normative propositions can be formulated. Astronomers accept a certain definition of planet, biologists have an accepted definition of DNA, and scientonomists have an accepted definition of theory.

In all these cases, the accepted definitions are not written in stone but rather change through time. Thus, in 2006, a new definition of planet was accepted by the International Astronomical Union which resulted in the famous demotion of Pluto from the status of a planet to a dwarf planet (Walton, 2008). Similarly, in 2017, a new definition of theory was accepted by scientonomy community which resulted in the inclusion of normative propositions into the category of theory. It is a basic historical fact that epistemic agents change their attitudes towards definitions and, therefore, there is nothing wrong in speaking of accepted or unaccepted definitions. The practice of our encyclopedia simply reflects this basic fact.

Since definitions can become accepted and since they are treated as a subtype of theory in the encyclopedia, it is my suggestion to include definitions into our theoretical ontology of epistemic elements as a subtype of theory. While the question of the precise definition of definition is not something that we must necessarily settle here, we can start with something very basic:

\section{Definition $\equiv$}

A statement of the meaning of a term.

Regardless of what we think of this somewhat simplistic definition, it is important to accept definitions as a subtype of theory. This step will allow us to further reduce the gap between our theoretical ontology and the ontology of the encyclopedia. It will also allow us to pose legitimate questions concerning the role of definitions in the process of scientific change.

One ramification of accepting definitions as a subtype of theory is the need to adjust the definition of theory acceptance such that it becomes applicable not only to descriptive and normative theories, but also to definitions. As readily seen, the current definition of the term (Sebastien, 2016, p. 7) is only applicable to descriptive and normative theories: 


\section{Theory Acceptance $\equiv$}

A theory is said to be accepted if it is taken as the best available description or prescription of its object.

Of course, in principle, we could turn the current "best available description or prescription of its object" to "the best available description, prescription, or definition of its object", but that solution would be far from ideal. Apart from sounding clumsy, it would prolong the rather regrettable practice of defining theory acceptance by alluding to subtypes of theory. As a result, we would have to continue redefining the term each time anything changed in the taxonomy of the subtypes of theory. I would like to take this opportunity and put an end to this practice which I myself helped in bringing about by explicitly including "best available description" in my initial definition of theory acceptance (Barseghyan, 2015, p. 31). To that end, I suggest we accept a definition that would be applicable to all types of theory and would not require modifications each time we change our views on the subtypes of theory. Consider the following definition:

\section{Theory Acceptance $\equiv$}

A theory is said to be accepted by an epistemic agent if it is taken as the best available answer to its respective question.

As any theory is an attempt to answer a certain question, to accept a theory amounts to considering it the best available answer to its respective question. This notion of theory acceptance can be easily specified for different subtypes of theory. For a descriptive theory, being accepted amounts to being considered the best available description/explanation/prediction of its object. For a normative theory, being accepted means being taken as the best available evaluation/prescription of its object. Finally, for a definition, being accepted amounts to being considered the best available definition of the term. The new definition can be similarly interpreted for any subtype of theory, including methods, ethical norms, etc.

\section{Scientific Mosaic}

There is one final question we have to address here: what happens to the notion of scientific mosaic now that questions are introduced into the scientonomic ontology of epistemic elements and methods are subsumed under the class of theories? Consider the current definition of scientific mosaic (Barseghyan, 2015, p. 5):

\begin{tabular}{|c|}
\hline Scientific Mosaic $\equiv$ \\
\hline A set of all accepted \\
theories and \\
employed methods. \\
\hline
\end{tabular}

The previous discussion makes the flaws of this definition apparent. Of course, its most obvious deficiency is that it is not compatible with the new scientonomic ontology where questions are a distinct class of epistemic elements. If the ontology of epistemic elements suggested in this paper becomes accepted, the current definition of scientific mosaic as a set of all accepted theories and employed methods will also have to be changed to reflect the new ontology. Yet, I believe, there is a deeper and more systematic flaw with the definition - the fact that it has the types of epistemic elements hard-wired in it. Let's consider this flaw in more detail.

As mentioned earlier, The Laws of Scientific Change didn't have a special discussion of the ontology of scientific change. Instead, most elements of the initial scientonomic ontology were introduced through their respective definitions in section Scope (Barseghyan, 2015, pp. 3-79). This goes for the acceptance, use, and pursuit as the three stances one can take towards a theory. This also goes for employment as a stance that can be 
taken towards a method. Importantly, this also goes for theory and method as two types of epistemic elements. The diagram that provides the definition of scientific mosaic also happens to be the diagram that introduces the two types of epistemic elements - theories and methods (Barseghyan, 2015, p. 5):

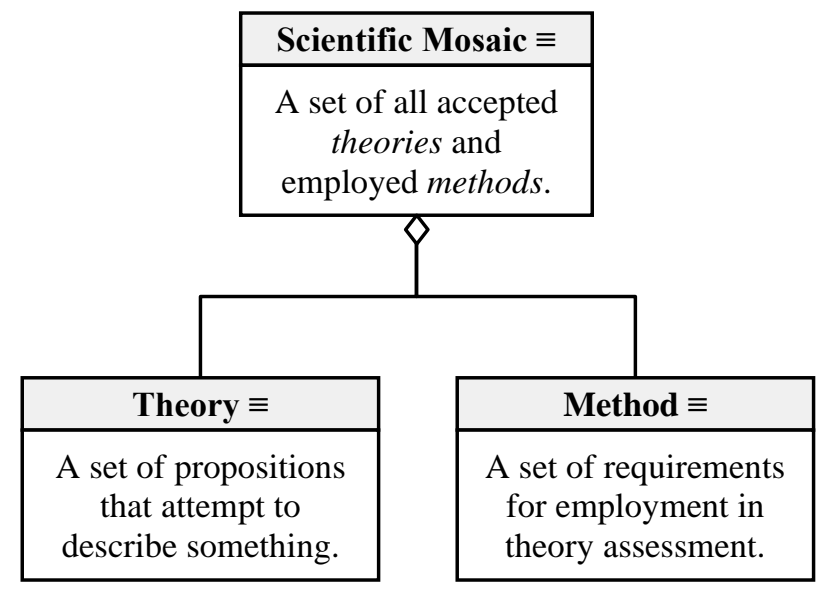

In short, the book didn't contain a proper statement of the ontology of scientific change but, for the most part, introduced that ontology through a series of discussions scattered across the first chapter - mostly through the definitions of the respective ontological concepts.

This is problematic, since any ontology of any field is not merely a set of definitions but also contains a statement of what sorts of entities and relations supposedly populate the domain under study. In other words, an ontology contains not only definitions of entities and relations, but also descriptive propositions stating that those entities and relations actually exist. For example, the ontology of the standard model doesn't merely define what it means by fermion, boson, quark, or lepton. Importantly, it also tells us that these types of subatomic particles populate physical reality. In other words, it contains not only the definitions of these classes of elements, but also descriptive propositions that state the reality of these types of elements, such as "the two fundamental classes of elementary particles that populate physical reality are elementary fermions and elementary bosons", "quarks and leptons are the two subtypes of elementary fermions", or "gauge bosons and scalar bosons are the two subtypes of elementary bosons". Unlike the definitions of quark, lepton, or boson, these descriptive propositions are contingent, i.e. they are hypotheses about the structural elements of physical reality. Similarly, when we say that "questions and theories are the two fundamental types of epistemic elements", we are suggesting a hypothesis about the structural elements of our domain, i.e. we are making a descriptive claim about theories and methods which is not the same as simply defining these concepts. Thus, any ontology contains not only some definitions, but also descriptive propositions attempting to list the types of entities and relations of its respective domain.

Therefore, an ontology cannot be postulated through definitions. Specifically, the ontology of epistemic elements cannot be stipulated by means of a definition of scientific mosaic, for it can only be done through descriptive propositions, such as "the two fundamental types of epistemic elements that undergo scientific change are questions and theories". This paper is essentially an attempt to suggest a series of such descriptive propositions concerning the ontology of scientific change.

The only thing that remains to be done here is to redefine the concept of scientific mosaic, to ensure that it is free of the aforementioned flaws. The question is how exactly it is to be altered? First, the new definition should make it possible for questions to be part of a mosaic. Second, the new definition should stay away from making any implicit descriptive claims concerning the ontology of epistemic elements, as was the case with the previous definition. I suggest the following definition: 


\section{Scientific Mosaic $\equiv$}

A set of all epistemic elements accepted and/or employed by an epistemic agent.

As can be seen, this definition doesn't explicitly mention any types of epistemic elements, which makes it possible for any accepted and/or employed element to be part of a mosaic. This is a clear advantage, since we will no longer have to change the definition of scientific mosaic every time we discover a new type of epistemic element. Also, as scientonomy has traditionally been interested in accepted and employed elements, the definition explicitly mentions only these two stances. Consequently, it says that a mosaic doesn't include used or pursued elements. This corresponds to the current scientonomic dynamics which is all about acceptance and employment. Finally, it explicitly mentions that epistemic agents can bear mosaics, but remains agnostic concerning the types of epistemic agents that can bear a mosaic. The latter is an important ontological question, the answer to which is necessarily a descriptive proposition stating that "the types of epistemic agents are...". Such a descriptive proposition is not to be smuggled in through a definition. All in all, the new definition is a good fit for the new ontology of epistemic elements and, therefore, is an improvement over the previous definition.

\section{Conclusion}

The currently accepted scientonomic ontology is flawed in a number of ways. First, it doesn't include definitions as a subtype of theory and, thus, differs from the ontology that is in the backbone of the Encyclopedia of Scientonomy. In addition, it distinguishes between two classes of elements - methods and methodologies - based on their respective historical fates rather than their propositional contents. This results in a somewhat absurd practice when the same criterion of theory evaluation can be classified either as a theory or as a method depending on whether it has or hasn't been historically accepted and/or employed. Furthermore, the currently accepted ontology relies heavily on the distinction between implicit and tacit, whereas the current analysis shows that all epistemic elements and stances can be both explicit and implicit and, therefore, implicitness or explicitness cannot be grounds for drawing ontological distinctions. Consequently, we need to accept a new scientonomic ontology which doesn't confuse the propositional content of an element with the historical records of its acceptances and/or employments.

The new ontology suggested in this paper helps solve some of the issues permeating the current ontology. First, it builds on Rawleigh's suggestion to include questions as a distinct class of epistemic elements and considers a theory as an attempt to answer a certain question. Second, it appreciates that because method is defined as a set of criteria for theory evaluation, methods are not an independent epistemic element but are a subtype of normative theories. Third, it suggests that because methods and methodologies of the currently accepted ontology do not differ from the perspective of their propositional content (i.e. both are criteria for theory evaluation), they in fact belong to one and the same class of epistemic elements. I suggested to reserve the word "method" for this type of epistemic element, and use "methodology" to denote the respective normative discipline. Fourth, it stipulates that methods can be both accepted and employed. However, it notes that the ability of being employed is not peculiar exclusively to methods, but characterizes normative propositions of all kinds, including ethical norms, aesthetic norms, and technological guidelines. Fifth, it introduces definitions as a subtype of theory. Finally, it redefines scientific mosaic to fit the new ontology. The resulting ontology can be depicted in the following UML diagram: 


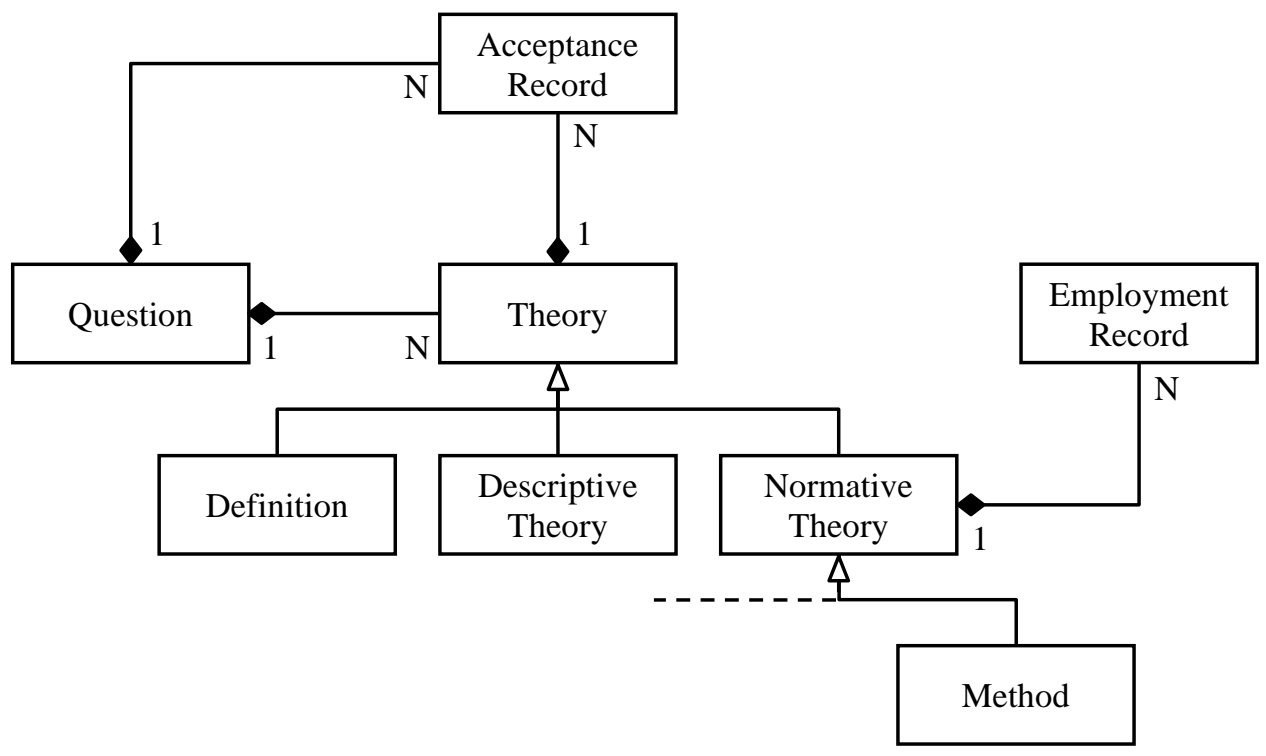

Importantly, the changes suggested in this paper are ontological only; they don't intend to change the gist of the current laws of scientific change. Although in the new ontology method is a subtype of normative theory, all the laws and theorems that concern methods remain intact. As for the laws and theorems concerning theory acceptance and rejection, they now also pertain to methods which are now understood as a subtype of normative theory. Thus, since the second law applies to all cases of theory acceptance, it also applies to method acceptance (which is obviously not to be confused with method employment). This outcome shouldn't shock us, since "accepted method" of the new ontology roughly corresponds to what was previously known as "openly prescribed methodology". In the language of the old scientonomic ontology (the one I hope this new ontology will come to replace), we could speak of methodologies becoming accepted in accord with the second law. Now, in the new ontology, we say that methods become accepted in accord to the second law. As for method employment, it is still governed by the third law. In short, the suggested ontology does not alter the formulations of the accepted scientonomic laws and theorem. The new ontology clearly makes it possible to deduce a plethora of new theorems, such as the method acceptance theorem, but that is not something this paper is concerned with.

While hopefully this paper answers a number of important questions and greatly reduces the gap between the ontology of theoretical scientonomy and that of the encyclopedia, it also suggests several questions for future research. First, if we say that theories can be accepted, used, and/or pursued, can we say the same about questions? In other words, is it the case that questions can only be accepted/unaccepted, or are there also other stances that an agent can take towards a question, such as using it or pursuing it? Second, if we say that any epistemic stance can be taken both explicitly and implicitly, is it important from the practical perspective to trace when a certain stance towards a certain epistemic element was taken explicitly and when it was taken implicitly? Should observational scientonomy record not only the fact that, say, a theory was accepted by a certain community at a certain period, but also tell us whether it was accepted explicitly or implicitly? What are the practical considerations for and against collecting and storing this data? Finally, if we are accepting definitions as a subtype of theory, then what is the relation between definitions and other subtypes of theory, namely, descriptive and normative theories? Are definitions indeed a distinct subtype of theory, or are they in some way reducible to, or expressible through descriptive or normative propositions? Addressing these questions is an important next step, but we can only take that step once we accept the new ontology suggested in this paper.

\section{Acknowledgments}

I would like to thank Gregory Rupik, Nicholas Overgaard, Paul Patton, and Jamie Shaw who greatly contributed to the development of the ideas presented in this paper during numerous brainstorming sessions. 


\section{Suggested Modifications}

\section{[Sciento-2018-0005]}

Accept the following definitions of method and methodology:

- Method $\equiv$ a set of criteria for theory evaluation.

\begin{tabular}{|c|}
\hline Method $\equiv$ \\
\hline $\begin{array}{c}\text { A set of criteria for } \\
\text { theory evaluation. }\end{array}$ \\
\hline
\end{tabular}

- Methodology $\equiv$ a normative discipline that formulates the rules which ought to be employed in theory assessment.

\begin{tabular}{|c|}
\hline Methodology $\equiv$ \\
\hline $\begin{array}{c}\text { A normative discipline that formulates } \\
\text { the rules which ought to be employed } \\
\text { in theory assessment. }\end{array}$ \\
\hline
\end{tabular}

Reject the previous definitions of method and methodology.

\section{[Sciento-2018-0006]}

Accept the following ontology of epistemic elements, where:

- Each theory is an attempt to answer a certain question.

- Theories can be of three types - descriptive, normative, or definitions.

- Method is a subtype of normative theory.

- Questions as well as theories of all types - including methods - can be accepted.

- Normative theories of all types can be employed; the name of the stance is norm employment.

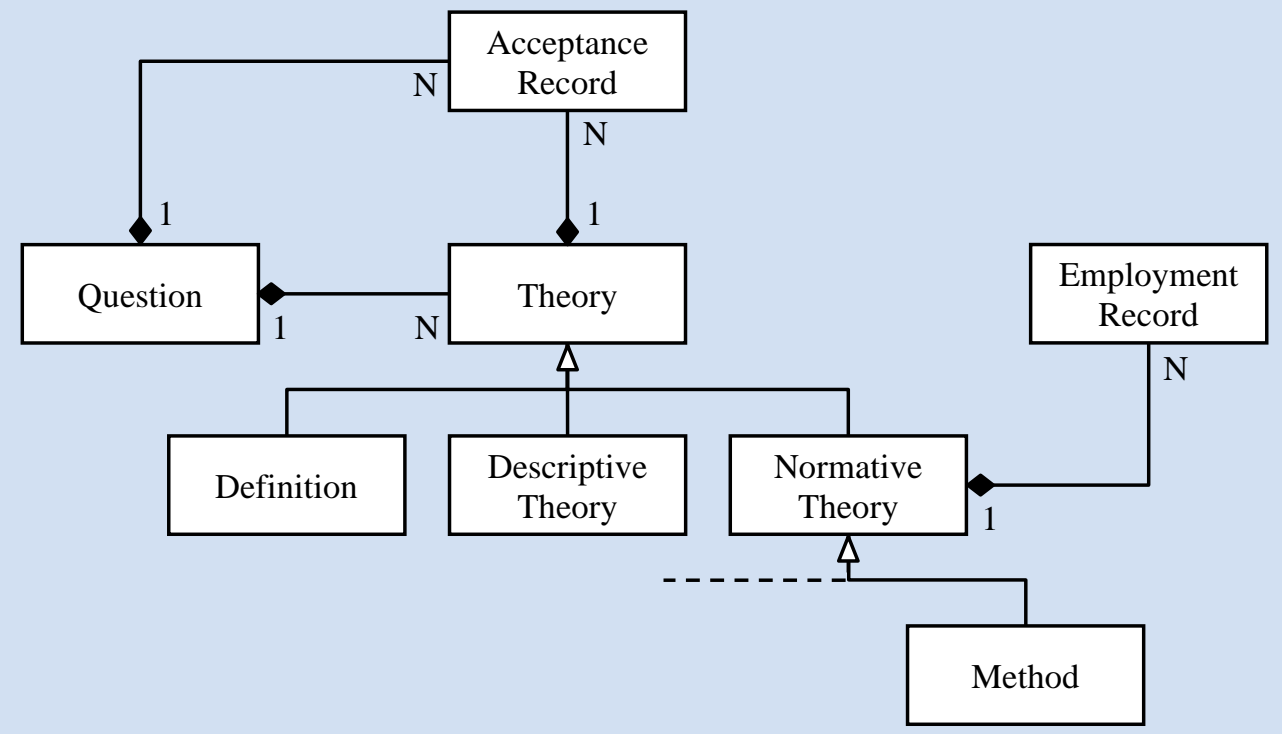

Accept the following definition of theory acceptance:

- Theory Acceptance $\equiv$ a theory is said to be accepted by the epistemic agent if it is taken as the best available answer to its respective question. 


\section{Theory Acceptance $\equiv$}

A theory is said to be accepted by an epistemic agent if it is taken as the best available answer to its respective question.

Also accept the following questions as legitimate topics of inquiry:

- Role of Definitions in Scientific Change: Do definitions play any distinct role in the process of scientific change, or do they only exhibit the exact same patterns as descriptive and normative theories?

- Reducibility of Definitions: Are definitions a distinct subtype of theory, or are they somehow reducible to descriptive theories and/or normative theories?

Reject the previous ontology of epistemic elements and the previous definition of theory acceptance.

\section{[Sciento-2018-0007]}

Accept the following definition of definition:

- Definition $\equiv$ A statement of the meaning of a term.

\begin{tabular}{|c|}
\hline Definition $\equiv$ \\
\hline $\begin{array}{l}\text { A statement of the } \\
\text { meaning of a term. }\end{array}$ \\
\hline
\end{tabular}

\section{[Sciento-2018-0008]}

Provided that modification [Sciento-2018-0006] is accepted, accept the following definition of norm employment:

- Norm Employment $\equiv$ a norm is said to be employed if its requirements constitute the actual expectations of the epistemic agent.

\begin{tabular}{|c|}
\hline Norm Employment $\equiv$ \\
\hline $\begin{array}{c}\text { A norm is said to be employed if its } \\
\text { requirements constitute the actual } \\
\text { expectations of an epistemic agent. }\end{array}$ \\
\hline
\end{tabular}

\section{[Sciento-2018-0009]}

Accept the new definition of scientific mosaic:

- Scientific Mosaic $\equiv$ a set of all epistemic elements accepted and/or employed by the epistemic agent.

\begin{tabular}{|c|}
\hline Scientific Mosaic $\equiv$ \\
\hline $\begin{array}{c}\text { A set of all epistemic elements } \\
\text { accepted and/or employed by } \\
\text { an epistemic agent. }\end{array}$ \\
\hline
\end{tabular}

Reject the previous definition of scientific mosaic. 


\section{[Sciento-2018-0010]}

Accept that:

- Epistemic stances of all types can be taken explicitly and/or implicitly.

- Epistemic elements of all types can be explicit and/or implicit.

Accepted the following question as a legitimate topic of inquiry:

- Tracing Implicit/Explicit: Should observational scientonomy trace when a certain stance towards an epistemic element was taken explicitly or implicitly? What are the practical considerations for and against collecting and storing this data?

\section{References}

Alchourrón, C. E. \& Martino, A. A. (1990). Logic Without Truth. Ratio Juris 3(1), pp. 46-67.

Ayer, A. J. (1949). On the Analysis of Moral Judgements. In Ayer (1954), pp. 231-249.

Ayer, A. J. (1954). Philosophical Essays. Palgrave Macmillan.

Barseghyan, H. (2015). The Laws of Scientific Change. Springer.

Barseghyan, H. \& Mirkin, M. (2019). The Role of Technological Knowledge in Scientific Change. In Héder \& Nádasi (Eds.) (2019), pp. 5-17.

Barseghyan, H. \& Shaw, J. (2017). How Can a Taxonomy of Stances Help Clarify Classical Debates on Scientific Change? Philosophies 2(4), 24. Retrieved from http://www.mdpi.com/2409-9287/2/4/24.

Bicchieri, C. \& Muldoon, R. (2014). Social Norms. In Zalta, E. N. (Ed.) (2014). Stanford Encyclopedia of Philosophy (Spring 2014 Edition). Retrieved from https://plato.stanford.edu/archives/spr2014/entries/social-norms/.

Carnap, R. (1958). Introduction to Symbolic Logic and its Applications. Dover Publications.

Chomsky, N. (2017). The Language Capacity: Architecture and Evolution. Psychonomic Bulletin \& Review 24(1), pp. 200203.

Davies, M. (2015). Knowledge (Explicit and Implicit): Philosophical Aspects. In Wright (Ed.) (2015), pp. 8126-8132.

Deslauriers, M. (2007). Aristotle on Definition. Brill.

Dixon, J.; Durrheim, K.; \& Tredoux, C. (2007). Intergroup Contact and Attitudes Toward the Principle and Practice of Racial Equality. Psychological Science 18(10), pp. 867-872.

Dubislav, W. (1937). Zur Unbegründbarkeit der Forderunssätze. Theoria 3, pp. 330-342.

Dummett, M. (1991). The Logical Basis of Metaphysics. Harvard University Press.

Fantl, J. (2017). Knowledge How. In Zalta, E. N. (Ed.) (2017). The Stanford Encyclopedia of Philosophy (Fall 2017 Edition). Retrieved from https://plato.stanford.edu/archives/fall2017/entries/knowledge-how/.

Fine, A. (2017). The Einstein-Podolsky-Rosen Argument in Quantum Theory. In Zalta, E. N. (Ed.) (2017). The Stanford Encyclopedia of Philosophy (Winter 2017 Edition). Retrieved from https://plato.stanford.edu/archives/win2017/entries/qtepr/.

Føllesdal, D. \& Hilpinen, R. (1971). Deontic Logic: An Introduction. In Hilpinen (Ed.) (1971), pp. 1-35.

Goldhaber, M. (1975). Tacit Assumptions in Fundamental Particle Physics. Proceedings of the American Philosophical Society 119(1), pp. 24-28.

Grobstein, P. (1990). Strategies for Analyzing Complex Organization in the Nervous System: I. Lesion Experiments. In Schwartz (Ed.) (1990), pp. 19-37.

Grue-Sörensen, K. (1939). Imperativsätze und Logik. Begegnung einer Kritik. Theoria 5, pp. 195-202.

Gupta, A. (2015). Definitions. In Zalta, E. N. (Ed.) (2015). Stanford Encyclopedia of Philosophy (Summer 2015 Edition). Retrieved from https://plato.stanford.edu/archives/sum2015/entries/definitions/.

Héder, M. \& Nádasi, E. (Eds.) (2019). Essays in Post-Critical Philosophy of Technology. Vernon Press.

Hilpinen, R. (2006). Norms, Normative Utterances, and Normative Propositions. Análisis Filosófico XXVI(2), pp. $229-276$.

Hilpinen, R. (Ed.) (1971). Deontic Logic: Introductory and Systematic Readings. D. Reidel Publishing Company.

Hofstadter, A. \& McKinsey, J. C. C. (1939). On the Logic of Imperatives. Philosophy of Science 6, pp. $446-57$.

Jørgensen, J. (1937). Imperatives and Logic. Erkenntnis 7, pp. 288-296.

LaPiere, R. T. (1934). Attitudes vs. Actions. Social Forces 13, pp. 230-237.

Macagno, F. \& Walton, D. (2010). The Argumentative Uses of Emotive Language. Revista Iberoamericana de Argumentación 1, pp. 1-33. 
McNamara, P. (2014). Deontic Logic. In Zalta, E. N. (Ed.) (2014). Stanford Encyclopedia of Philosophy (Winter 2014 Edition). Retrieved from https://plato.stanford.edu/archives/win2014/entries/logic-deontic/.

Overgaard, N. (2017). A Taxonomy for the Social Agents of Scientific Change. Scientonomy 1, pp. 55-62. Retrieved from https://www.scientojournal.com/index.php/scientonomy/article/view/28234.

Patton, P.; Overgaard, N.; \& Barseghyan, H. (2017). Reformulating the Second Law. Scientonomy 1, pp. 29-39. Retrieved from https://www.scientojournal.com/index.php/scientonomy/article/view/27158.

Polanyi, M. (1958). Personal Knowledge: Towards a Post-Critical Philosophy. Routledge.

Rawleigh, W. (2018). The Status of Questions in the Ontology of Scientific Change. Scientonomy 2, pp. 1-12. Retrieved from https://scientojournal.com/index.php/scientonomy/article/view/29651.

Rey, A. (2000). Defining Definition. In Sager (Ed.) (2000), pp. 1-14.

Rutte, H. (1991). Ethics and the Problem of Value in the Vienna Circle. In Uebel (Ed.) (1991), pp. 143-157.

Ryle, G. (1949). The Concept of Mind. The University of Chicago Press.

Sager, J. C. (Ed.) (2000). Essays on Definition. John Benjamins Publishing Company.

Schwartz, E. L. (Ed.) (1990). Computational Neuroscience. MIT Press.

Sebastien, Z. (2016). The Status of Normative Propositions in the Theory of Scientific Change. Scientonomy 1, pp. 1-9. Retrieved from https://www.scientojournal.com/index.php/scientonomy/article/view/26947.

Stevenson, C. L. (1944). Ethics and Language. Yale University Press.

Stich, S. P. (1978). Beliefs and Subdoxastic States. Philosophy of Science 45(4), pp. 499-518.

Uebel, T. (Ed.) (1991). Rediscovering the Forgotten Vienna Circle. Kluwer Academic Publishers.

Volpe, G. (1999). A Minimalist Solution to Jørgensen's Dilemma. Ratio Juris 12(1), pp. 59-79.

von Wright, G. H. (1963). Norm and Action. Routledge and Kegan Paul.

Walton, D. (2008). Arguing from Definition to Verbal Classification: The Case of Redefining 'Planet' to Exclude Pluto. Informal Logic 28(2), pp. 129-154.

Weingartner, P. (1965). Can One Say of Definitions that They Are True or False? Ratio 7, pp. 61-93.

Weingartner, P. (2000). Basic Questions on Truth. Springer.

Wicker, A. W. (1969). Attitude versus Actions: The Relationship of Verbal and Overt Behavioral Responses to Attitude Objects. Idea: A Journal of Social Issues 25, pp. 41-78.

Wright, J. D. (Ed.) (2015). International Encyclopedia of the Social \& Behavioral Sciences (Second Edition). Elsevier. 